\title{
Dynamical geochemistry of the mantle
}

\author{
G. F. Davies \\ Research School of Earth Science, Australian National University, Canberra, ACT 0200, Australia
}

Received: 2 March 2011 - Published in Solid Earth Discuss.: 24 March 2011

Revised: 30 July 2011 - Accepted: 10 August 2011 - Published: 13 September 2011

\begin{abstract}
The reconciliation of mantle chemistry with the structure of the mantle inferred from geophysics and dynamical modelling has been a long-standing problem. This paper reviews three main aspects. First, extensions and refinements of dynamical modelling and theory of mantle processing over the past decade. Second, a recent reconsideration of the implications of mantle heterogeneity for melting, melt migration, mantle differentiation and mantle segregation. Third, a recent proposed shift in the primitive chemical baseline of the mantle inferred from observations of non-chondritic ${ }^{142} \mathrm{Nd}$ in the Earth. It seems most issues can now be resolved, except the level of heating required to maintain the mantle's thermal evolution.

A reconciliation of refractory trace elements and their isotopes with the dynamical mantle, proposed and given preliminary quantification by Hofmann, White and Christensen, has been strengthened by work over the past decade. The apparent age of lead isotopes and the broad refractory-element differences among and between ocean island basalts (OIBs) and mid-ocean ridge basalts (MORBs) can now be quantitatively accounted for with some assurance.

The association of the least radiogenic helium with relatively depleted sources and their location in the mantle have been enigmatic. The least radiogenic helium samples have recently been recognised as matching the proposed nonchondritic primitive mantle. It has also been proposed recently that noble gases reside in a so-called hybrid pyroxenite assemblage that is the result of melt from fusible pods reacting with surrounding refractory peridotite and refreezing. Hybrid pyroxenite that is off-axis may not remelt and erupt at MORs, so its volatile constituents would recirculate within the mantle. Hybrid pyroxenite is likely to be denser than average mantle, and thus some would tend to settle in the $\mathrm{D}^{\prime \prime}$
\end{abstract}

zone at the base of the mantle, along with some old subducted oceanic crust. Residence times in $\mathrm{D}^{\prime \prime}$ are longer, so the hybrid pyroxenite there would be less degassed. Plumes would sample both the degassed, enriched old oceanic crust and the gassy, less enriched hybrid pyroxenite and deliver them to OIBs. These findings can account quantitatively for the main $\mathrm{He}, \mathrm{Ne}$ and $\mathrm{Ar}$ isotopic observations.

It has been commonly inferred that the MORB source is strongly depleted of incompatible elements. However it has recently been argued that conventional estimates of the MORB source composition fail to take full account of mantle heterogeneity, and in particular focus on an ill-defined "depleted" mantle component while neglecting less common enriched components. Previous estimates have also been tied to the composition of peridotites, but these probably do not reflect the full complement of incompatible elements in the heterogeneous mantle. New estimates that account for enriched mantle components suggest the MORB source complement of incompatibles could be as much as 50-100\% larger than previous estimates.

A major difficulty has been the inference that mass balances of incompatible trace elements could only be satisfied if there is a deep enriched layer in the mantle, but the Earth's topography precludes such a layer. The difficulty might be resolved if either the Earth is depleted relative to chondritic or the MORB source is less depleted than previous estimates. Together these factors can certainly resolve the mass balance difficulties. 


\section{Introduction}

As the physical structure and dynamical behaviour of the mantle have become clearer, several aspects of mantle geochemistry have remained enigmatic, leading to divergent models that have not simultaneously satisfied the geophysical and geochemical constraints. Whereas geophysical inferences have led to a picture of the mantle with no major vertical compositional variation, apart from the $\mathrm{D}^{\prime \prime}$ zone in the lowest 200-300 km (Davies and Richards, 1992; Grand et al., 1997; Davies, 1999b), geochemical constraints have frequently been deemed to require a thick, hidden layer relatively enriched in incompatible elements, including the noble gases, in order to satisfy mass balance requirements (Allegre et al., 1996; Kellogg et al., 1999). Such a layer is not only not required by the geophysical evidence, it is precluded, though this has not been widely appreciated.

Three lines of research have developed in parallel over the past few years that, between them, promise to reconcile most aspects of mantle chemistry with the geophysically-inferred mantle picture. First, a fuller consideration of the implications of the major-element heterogeneity of the mantle has loosened the apparent constraints on mantle composition and mass balances, and in the processes suggested mantle locations of noble gases (Davies, 2009b, 2010). Second, the observation that ${ }^{142} \mathrm{Nd} /{ }^{144} \mathrm{Nd}$ is distinctly higher in Earth than in chondritic meteorites (Boyet and Carlson, 2005) has led to the inference that the observable mantle is more depleted in incompatible and volatile elements than the chondritic standard (Boyet and Carlson, 2006; Carlson and Boyet, 2008), and the whole Earth may be non-chondritic (Caro and Bourdon, 2010). This potential shift of the primitive baseline may reduce the need for a hidden layer, and it has led to the identification of a vestigial mantle component that would be primitive in both refractory elements and noble gases (Caro and Bourdon, 2010; Jackson et al., 2010). Third, models and theories of chemical tracers in the geophysical mantle have appeared over the past decade in a series of separate and sometimes technical papers that may not be very accessible to a broader audience. This paper reviews these developments. It argues that most of the main geochemical observations may be reconciled with the geophysical Earth model, whether the Earth is chondritic or not.

The refractory trace elements and their isotopes have by now been quite well reconciled with the geophysical mantle, apart from the mass balance question, starting from the hypothesis of Hofmann and White (1982). They proposed that ancient, subducted oceanic crust is recycled to the Earth's surface via the $\mathrm{D}^{\prime \prime}$ zone and mantle plumes, and they argued that the enrichment of many OIBs relative to MORBs was due to this component of old oceanic crust. This scenario was quantified by in numerical models by Christensen and Hofmann (1994), and they found that subducted oceanic crust, which is denser than average mantle, does indeed tend to segregate to the bottom, and that its average residence time was permissive of the apparent age of $1.8 \mathrm{Ga}$ evident in lead isotopes. Subsequent work, reviewed here, has rectified significant deficiencies in Christensen and Hofmann's pioneering modelling and has found that segregation of subducted oceanic crust and appropriate residence times occur quite generally. This work has thus strengthened the quantitative case supporting this interpretation.

The place of noble gases in the mantle has been one of the most enigmatic aspects of mantle geochemistry. The association of the least radiogenic helium with isotopic signatures of the recently-proposed non-chondritic primitive mantle plausibly identifies a source type, but still leaves questions about the mantle location and residence times of noble gases. A proposal by Tolstikhin and Hofmann (2005) that primitive helium is contained in an altered and foundered early mafic crust now residing in $\mathrm{D}^{\prime \prime}$ depends on assumptions that are difficult to substantiate, and it may not be consistent with the non-chondritic Earth interpretation.

Recently it has been argued (Davies, 2009b, 2010) that mass balance questions can be resolved and noble gas evolution clarified and quantified by starting from the widelyaccepted expectation that the mantle is heterogeneous on many scales in both major and trace elements. This strongly affects mantle melting, melt migration, and the extraction of incompatible elements from the mantle, with the implication that previous estimates of mantle composition are lower bounds on concentrations of incompatible elements.

One major question about the mantle's composition remains. The abundance of heat-producing elements (principally $\mathrm{U}$, Th and $\mathrm{K}$ ) does not seem to be sufficient to sustain the thermal evolution of the mantle obtained from conventional thermal evolution calculations, either parameterised or numerical. Several possible resolutions of this question have been advocated, and they will be briefly discussed. However the question seems yet to be persuasively resolved.

\section{The geophysical mantle}

The broad structure of the mantle inferred from geophysical constraints is illustrated in Fig. 1, with dynamical elements and schematic geochemical heterogeneity (Davies, 1990b). Included are subducting lithosphere and rising mantle plumes, each of which is the active component of a mode of mantle convection (Davies, 1999b, 2011).

The only significant vertical compositional variation is at the base, where the so-called $\mathrm{D}^{\prime \prime}$ layer, about $200-300 \mathrm{~km}$ thick, is interpreted to be compositionally denser and also probably to have a phase transformation within it (Lay et al., 1998; Hirose, 2006). It is also, by inference, part of a thermal boundary layer where heat is conducting from the core (Lay et al., 2008). A suggestion in the sketch of a gradient of heterogeneity through the lower third of the mantle is not directly supported by later models, though it could 


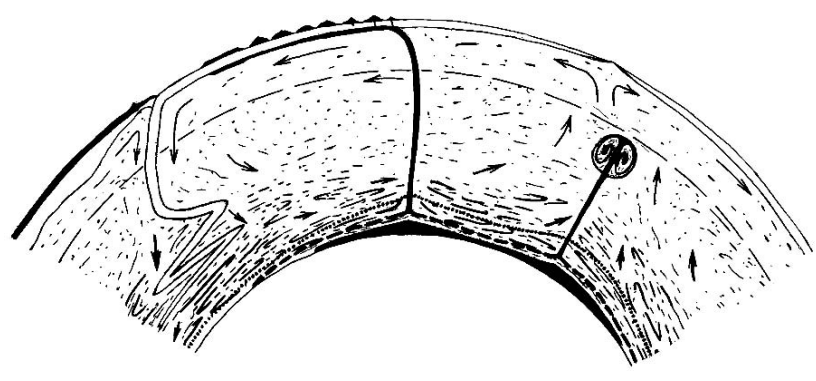

Fig. 1. Sketch of the mantle, with lithosphere and continental crust roughly to scale. The main dynamical elements of the mantle are included: subducting lithosphere and rising mantle plumes. Arrows indicate the flow associated with the plates. Chemical heterogeneity is included schematically. The $\mathrm{D}^{\prime \prime}$ at the bottom includes a discontinuous denser layer (black), plume feeding zone (heavy dashes) and thermal boundary layer (dotted). From Davies (1990b). Copyright Elsevier Science. Reprinted with permission.

represent piles of denser material that extend upwards under upwellings, as we will see in the discussion to follow.

The possibility of a compositional change through the transition zone, and especially at the $660 \mathrm{~km}$ seismic discontinuity, was resolved in the negative by two arguments. The first (Davies, 1988b) is that such a compositional boundary would give rise to plumes that are much stronger than is consistent with observed hotspot swells. This argument will be presented more fully in the context of mass balances (Sect. 7), but briefly the boundary would separate two convection layers, and heat would therefore have to conduct through the boundary, generating a hot thermal boundary layer above the $660 \mathrm{~km}$ boundary. Because little heat is inferred to be generated within the upper mantle, much of the Earth's heat budget would have to come from deeper, and would therefore be passing through this boundary layer. It would therefore generate buoyant upwellings whose strong buoyancy would generate surface topography comparable to the topography of the mid-ocean ridge system. No such topography exists. The only topography attributable to buoyant upwellings is the hotspot swells, whose amplitude implies quite directly that the upwellings generating them carry less than about $10 \%$ of the Earth's heat budget. This is consistent with current estimates of the heat coming from the core (Lay et al., 2008; Leng and Zhong, 2008). This implies, in turn, that mantle plumes rise without major impediment through the whole mantle.

The second argument is that seismic tomography detects subducted lithosphere extending from surface subduction zones through the transition zone and deep into the lower mantle (Grand et al., 1997). The associated mass flow implies that a compositional difference would be removed within less than a billion years (Davies, 1999a). Although it was the striking images from this study that persuaded many people that mantle convection operates as a single layer, both arguments are strong, and the first argument applies also to other proposed layers in the mantle, as we will see later.

This mantle structure is capable of explaining the two main dynamical features of the mantle, plate tectonics and mantle plumes, which are both forms of mantle convection. The form and kinematics of tectonic plates is explained by their effectively brittle rheology (Wilson, 1965; Davies, 1988a). The motion of plates is explained by the negative buoyancy of subducting plates (Turcotte and Oxburgh, 1967; Davies and Richards, 1992). Mantle plumes are a straightforward consequence of heat conducting from the core, and they explain the main features of volcanic hotspots and flood basalt eruptions (Davies, 1988b; Campbell and Griffiths, 1990; Griffiths and Campbell, 1990; Leitch and Davies, 2001). These points are also covered in (Davies, 1999b, 2011).

The question reviewed in this paper is whether geochemical observations of the mantle can be reconciled with this broad picture of mantle structure and dynamics.

\section{Refractory trace elements}

The roles of refractory trace elements and their isotopes in the mantle model just outlined are by now relatively well understood, following the hypothesis of Hofmann and White (1982) and the pioneering modelling by Christensen and Hofmann (1994). Further theoretical and numerical modelling over the past decade has strengthened the case for the Hofmann and White hypothesis, in which some subducted oceanic crust settles to the base of the mantle, later to be entrained in mantle plumes and contribute to eruptions at volcanic hotspots. It has also been shown that little remaining primitive mantle is to be expected.

A simple theory, validated by numerical models, has clarified the factors controlling the numerical results. It has been used to estimate the fraction of the mantle that has been processed through the melting zones under mid-ocean ridges and the proportion of subducted oceanic crust to be expected in the mantle. Extensions of such calculations have elucidated the factors that control the age distribution of subducted oceanic crust and its mean age in different mantle contexts.

\subsection{Remaining fraction of primitive mantle}

Mid-ocean ridges are the sites of mantle melting and the segregation of melt to form the oceanic crust, leaving a depleted zone below. The depth of main melting (i.e. the depth to the dry solidus) is about $60 \mathrm{~km}$, but minor melting or melting of heterogeneities might occur as deep as $110 \mathrm{~km}$ (Yasuda et al., 1994; Spandler et al., 2008). The present areal rate of seafloor spreading is $3 \mathrm{~km}^{2} \mathrm{yr}^{-1}$ (Parsons, 1982). The rate at which mantle mass is being processed through the MOR melting zone can then be calculated as

$\phi=\rho A_{\mathrm{S}} d_{m}$ 
where $\rho$ is the density of the upper mantle, $A_{\mathrm{S}}$ is the areal spreading rate and $d_{\mathrm{m}}$ is the melting depth. The time it would take to process one mantle mass, $M$, at this rate is then

$\tau=M / \phi$

This can be called the mantle processing time (Davies, 2002). With the above spreading rate, $d_{\mathrm{m}}=110 \mathrm{~km}$, a density of $3300 \mathrm{~kg} \mathrm{~m}^{-3}$ and a mantle mass of $4 \times 10^{24} \mathrm{~kg}$, the processing time is about $\tau=4 \mathrm{Gyr}$.

Because of higher radioactive heating in the past, the mantle would have been hotter, would have had a lower viscosity and so would have overturned faster. Davies (2002) estimated that, at present rates of overturn, it would have taken about $18 \mathrm{Gyr}$ to accomplish the number of overturns that have actually occurred within $4.5 \mathrm{Gyr}$. A "model time", $t_{\mathrm{m}}$, was defined to run in proportion to the rate of overturn. Davies also showed that the proportion, $p$, of the mantle that remains unprocessed declines exponentially with $t_{\mathrm{m}}$ :

$p=\exp \left(-t_{\mathrm{m}} / \tau\right)$

After $t_{\mathrm{m}}=18 \mathrm{Gyr}$, with $\tau=4 \mathrm{Gyr}, p=0.011$.

Thus by this estimate only about $1 \%$ of the mantle remains primitive. This fraction would be even smaller if the melting depth was greater in the past, because the mantle was hotter. Numerical calculations have yielded results consistent with this result (Davies, 2002, 2008). Thus most of the mantle will have been processed through the melting zone, and we cannot expect a substantial amount of primitive, unmelted mantle to have survived in the MORB source.

\subsection{Expected mantle heterogeneity}

It is widely acknowledged that the mantle is heterogeneous in major element composition and in mineral assemblage or lithology. In the upper mantle it is predominantly peridotite, with smaller proportions of eclogite and pyroxenite (Ringwood, 1975; Hofmann, 1997). With the advent of plate tectonics a straightforward explanation for this became evident: a subducting plate is a layered structure, with mafic oceanic crust on top and an ultramafic (peridotite) mantle section underneath, the latter variably depleted of the components removed by melting to form the crust. At depth the oceanic crust will exist as eclogite, and mantle convection will stir the two kinds of material.

One can readily estimate the amount of oceanic crust that has been subducted over time, but it will also have been removed by melting at mid-ocean ridges. As the amount builds up from zero in the mantle due to subduction, so more will melt, until an equilibrium is approached. Using logic similar to the previous section, the proportion of subducted crust in the mantle, $f$, will approach a maximum $f_{\mathrm{m}}=\varphi_{\mathrm{S}} / \varphi$ exponentially with $t_{\mathrm{m}}$, where $\phi_{\mathrm{S}}$ is the rate of subduction of oceanic crust:

$\phi_{\mathrm{S}}=\rho_{\mathrm{c}} A_{\mathrm{S}} d_{\mathrm{c}}$ where $\rho_{\mathrm{c}}$ is the density of oceanic crust and $d_{\mathrm{c}}$ is its thickness. Then at any model time, the proportion of crust in the mantle will be

$f=f_{\mathrm{m}}\left[1-\exp \left(-t_{\mathrm{m}} / \tau\right)\right]$

After 18 Gyr of model time $f$ will be $99 \%$ of $f_{\mathrm{m}}$, and with a crustal density of $2900 \mathrm{~kg} \mathrm{~m}^{-3}$ and thickness of $7 \mathrm{~km}$ this gives $f=0.06$. In other words the mantle should contain about $6 \%$ of subducted, unprocessed oceanic crust. As we will see later, not all crust melted under ridges may have been removed from the mantle, so the total amount of crustderived material may be about double this.

This result quantifies the expectation that, after several billion years of subducting oceanic crust plus underlying depleted mantle, the mantle will have substantial majorelement heterogeneity. Because the oceanic crust is enriched in incompatible trace elements relative to the mantle, this implies heterogeneity of trace elements as well.

\subsection{Stirring versus homogenising}

After the lithosphere has subducted, it will be stirred around the mantle by mantle convection. It has been a common presumption that the material will then be homogenised by mantle stirring. This presumption was behind early interpretations of trace-element heterogeneity: heterogeneity was taken to imply the existence of separate reservoirs in the mantle, because a convecting layer ought to be compositionally homogenised (Wasserburg and DePaolo, 1979). There are two reasons why this presumption is misleading.

First, rates of stirring in the mantle are very slow. (By "stirring" I mean here the intermingling of two kinds of material.) This is not only because mantle convection is slow, it is also because it involves only "cells" of the largest scale. In familiar fluids, such as water, momentum is significant compared with viscosity, and the result is that when water is stirred a cascade of vortices forms, down to quite small sizes. The combination of large and small vortices stirs the fluid much more rapidly. That is why a mixture of coffee and cream can be quickly homogenised. However in fluids in which viscosity is dominant, the small-scale vortices do not form, and the stirring must be accomplished only by the largest scale of flow. Imagine (or try) stirring a mixture of cream and cold honey: the fluids will intermingle, but they will require much more stirring to be homogenised.

The second reason homogenisation is very slow in the mantle was pointed out quite a long time ago: solid state diffusion rates are very slow, such that it will extend only over centimeters within a billion years (Hofmann and Hart, 1978). Unless the solid materials can be stretched and thinned down to the scale of centimeters, they will remain compositionally distinct for the age of the Earth. 


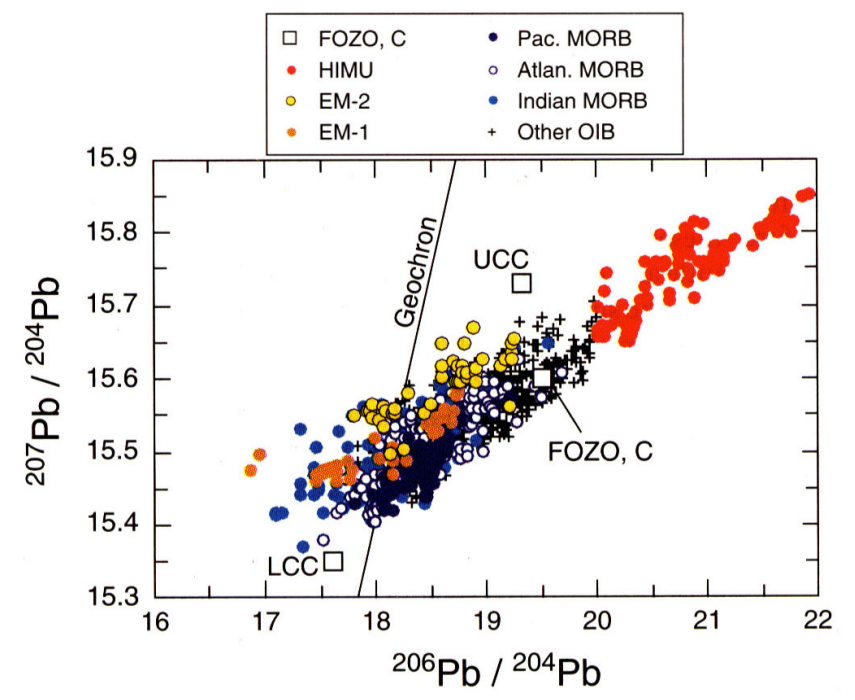

Fig. 2. Observed lead isotopic heterogeneity of mantle-derived rocks. FOZO, C: putative mean compositions; HIMU, EM-1, EM2: classes of OIBs; UCC: upper continental crust; LCC: lower continental crust; Geochron: locus of meteorite values. From Hofmann (1997). Reprinted from Nature with permission. Copyright Macmillan Magazines Ltd.

\subsection{Processing time versus homogenising time}

Lead isotopes from the mantle form an array (Fig. 2) whose slope can be interpreted as corresponding to an age of about 1.8 Ga (Chase, 1981; Hofmann, 1997). This implies in turn that mantle heterogeneities persist for this order of time. The apparent lead age has been interpreted in two different ways. One interpretation was that it represents the average time it takes to homogenise heterogeneities in the mantle. The other is that it is the average time between passages through a MOR melting zone, which would be the processing time defined in Eq. (2).

The homogenising time is quite sensitive to details of the flow, even if the flow is highly viscous. If mantle convection is unsteady and confined to the upper mantle, the homogenising time might be as short as $400 \mathrm{Myr}$ (Kellogg and Turcotte, 1990), whereas if mantle convection is relatively steady and occupying the whole mantle then heterogeneities persist for billions of years (Gurnis and Davies, 1986). Stirring is faster in three-dimensional flow than in two-dimensions (van Keken and Zhong, 1999). As a result it has been difficult to show that the homogenising time might correspond with the observed apparent lead age.

On the other hand, in the numerical modelling of Christensen and Hofmann (1994), and later work summarised below, the presumption has been that the apparent lead age represents the processing time. It is by now plausibly established that this interpretation is consistent with relevant observations, as we will see.

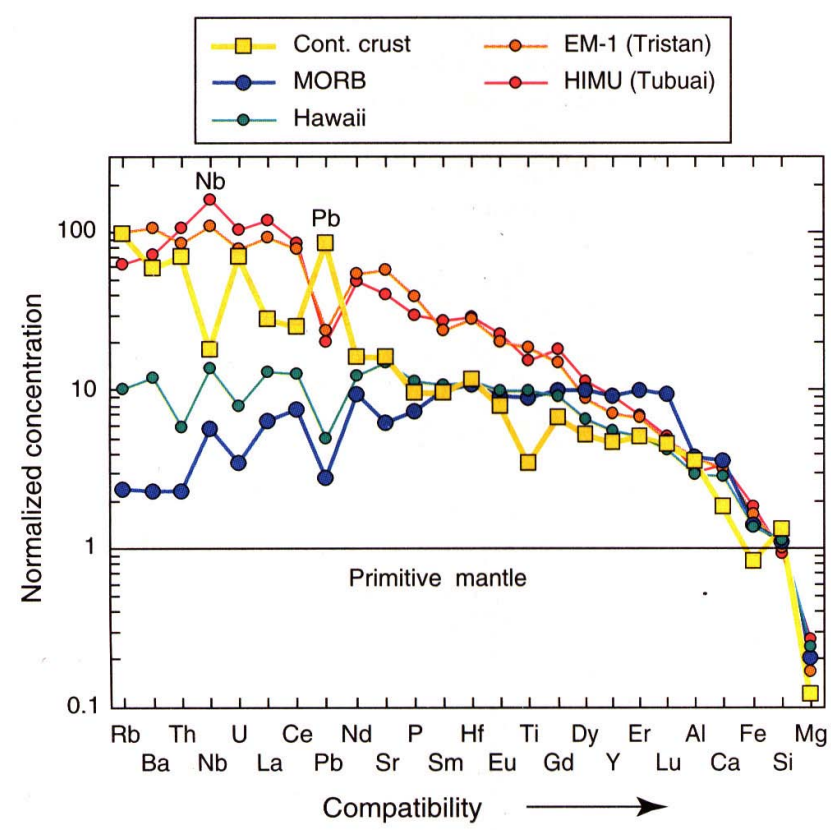

Fig. 3. Trace element concentrations in mantle-derived rocks. Concentrations are normalised to estimated concentrations in the primitive mantle. From Hofmann (1997). Reprinted from Nature with permission. Copyright Macmillan Magazines Ltd.

\subsection{Trace element heterogeneity in MORBs and OIBs}

OIBs typically have much higher concentrations of refractory incompatible trace elements than MORBs, though those from Hawaii are intermediate. Such observations are summarised in Fig. 3. It was this difference that motivated Hofmann and White (1982) to argue that OIBs contain a component of old oceanic crust that has been cycled through the mantle by subduction and subsequently returned in a mantle plume, spending some of the intervening time within the $\mathrm{D}^{\prime \prime}$ layer.

Christensen and Hofmann (1994) tested this hypothesis with a numerical model in which subducted oceanic crust was simulated with tracers carrying extra mass, to account for the higher density of subducted crust through most of the depth of the mantle (Hirose et al., 2005). They found that some of the subducted crust did indeed accumulate at the base of the model, though much of it remained suspended in the mantle interior. An example illustrating this behaviour from a more recent calculation (Davies, 2008) is shown in Fig. 4. Such models clearly support the Hofmann and White hypothesis, as they provide an accumulation of old oceanic crust in the $\mathrm{D}^{\prime \prime}$ region, where it might be entrained by plumes and ultimately contribute to OIBs.

However it is difficult to further quantify the process, for example by calculating how much old crust might be entrained into a plume, and how the elements might be partitioned as the plume melts near the surface. There will be 

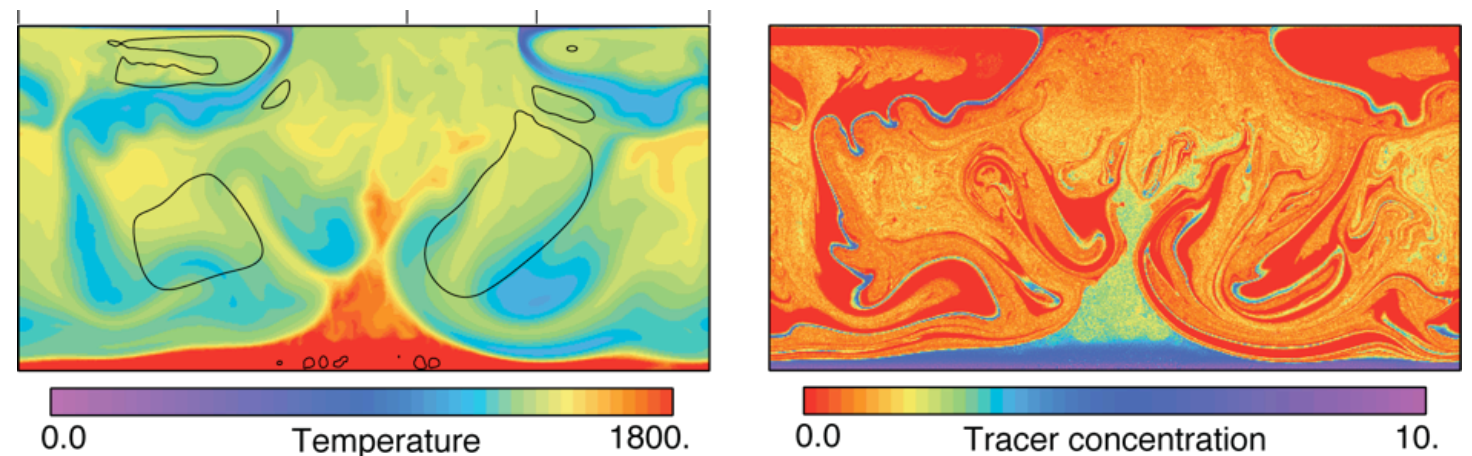

Fig. 4. Temperature and streamlines (left) and tracer concentrations (right) from a numerical model with tracers that represent subducted basaltic crust that is denser than average mantle by $150 \mathrm{~kg} \mathrm{~m}^{-3}$. A tracer concentration of 1 corresponds to the average basaltic content of the mantle. Red zones at the top are melted zones from which tracers have been removed to the oceanic crust. From Davies (2008): Case 1 after 2000 Myr. Copyright Elsevier Science. Reprinted with permission.

a limit to how much negatively buoyant crust material can be lifted by the thermal buoyancy of a plume, and the two kinds of buoyancy can induce complicated behaviour in a thermochemical plume, with the heavier material tending to drop out in the upper mantle (Farnetani and Samuel, 2005; Lin and van Keken, 2006; Kumagai et al., 2008). Detailed models of melting near the surface will also be difficult because the plume will be intrinsically heterogeneous (Kerr and Mériaux, 2004), a topic that will be discussed later.

\subsection{Isotopic heterogeneity}

The observed heterogeneity of lead isotopes is shown in Fig. 2, and the observed heterogeneity of neodymium and strontium isotopes is shown in Fig. 5, with symbols defined as in Fig. 2. These plots show that both OIBs and MORBs have a range of isotopic composition, though the MORB range is smaller by about a factor of two. Most of the variations evident in OIBs are also evident in MORBs, though with a smaller spread.

Isotopic heterogeneity occurs on all spatial scales, from global to grain-size. Heterogeneity of MORBs at the largest scale is evident in Figs. 2 and 5, where differences can be seen particularly between the Indian Ocean and the Pacific Ocean, with the Atlantic Ocean tending to be intermediate. Heterogeneity at intermediate scales, down to a few degrees of latitude, are evident along the Mid-Atlantic Ridge, Fig. 6. There are variations at the scale of a few degrees comparable to the variation along the entire ridge, for example near $14^{\circ} \mathrm{N}$. Large variations have also been found within single hand specimens (Hofmann, 2003), suggesting that such variations are present in the source, though they will tend to be homogenised within magma chambers during extraction.

Christensen and Hofmann (1994) and some later modellers (Xie and Tackley, 2004; Brandenburg et al., 2008) have calculated synthetic isotope plots from numerical models for comparison with observations. While this is a laudable approach in principle, Davies (2002) noted that there are considerable uncertainties in melting relationships, melt migration processes and scales of sampling that weaken these plots as probes of the source heterogeneity.

\subsection{Sampling heterogeneity versus mixing reservoirs}

The interpretation of plots of isotopic heterogeneity was influenced early by the common assumption that convecting layers would be homogenised. As a result the MORB data were frequently characterised as "remarkably uniform", but this owed more to circular definitions than to the actual spread of data, a point also emphasised by Hofmann (2003). The conception of homogenised convecting layers also implied to many that separate mantle reservoirs would be required to maintain heterogeneity. Consequently the spread of data in Figs. 2 and 5 was widely assumed to be due to mixing between end members, and much debate focussed on how many end members were necessary.

However homogenising times can be very long in mantle convection, as noted above, so heterogeneity in itself does not require separate reservoirs. The absence of geophysical evidence for mantle reservoirs, apart from $\mathrm{D}^{\prime \prime}$, and the continuous generation of mantle heterogeneity by subduction suggest an alternative interpretation of isotopic heterogeneity. Rather than representing mixing, the spread of data may directly reflect the spread of values in the source region.

This shift of perception has a large effect on how the mantle is interpreted. It is illustrated in Fig. 7. In the mixing interpretation, Fig. 7a, the emphasis is on identifying the extreme values, the "end members". In the direct sampling interpretation, the important parameters are the mean value and the spread, and the notion of a depleted end member is not relevant to determining the composition of the mantle. The most depleted samples merely represent the extreme of the depletion process, not an identifiable volume of the mantle. The huge emphasis on characterising a putative "depleted MORB 

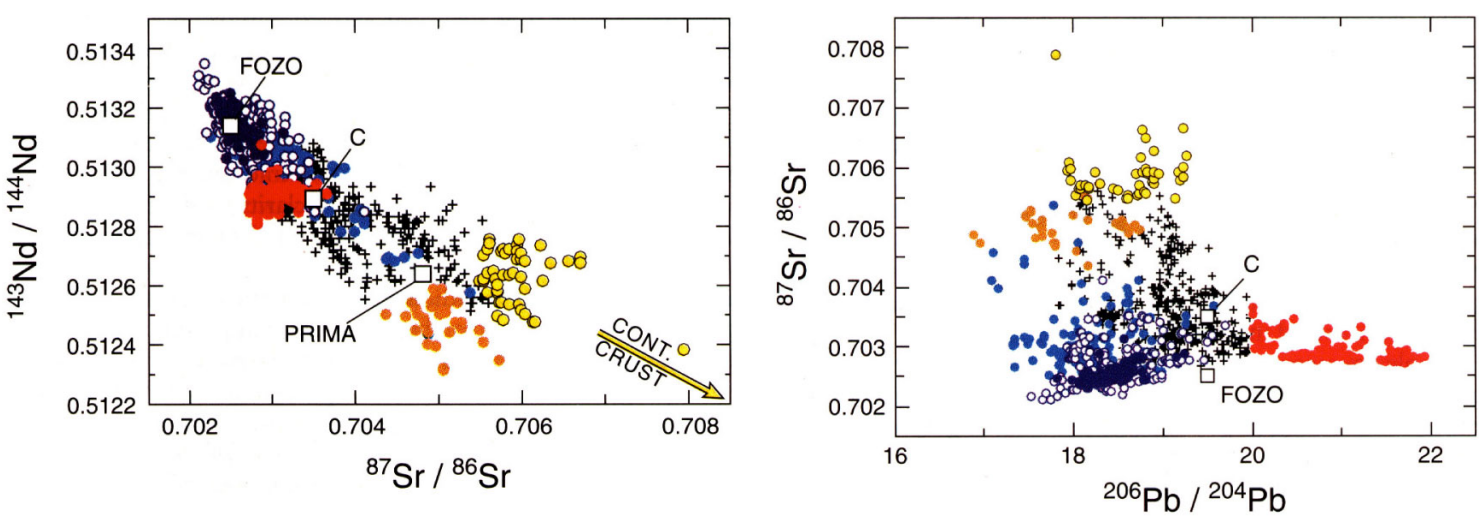

Fig. 5. Observed $\mathrm{Nd}$ and $\mathrm{Sr}$ isotopic heterogeneity of mantle-derived rocks. Legend and acronyms as in Fig. 2. From Hofmann (1997). Reprinted from Nature with permission. Copyright Macmillan Magazines Ltd.

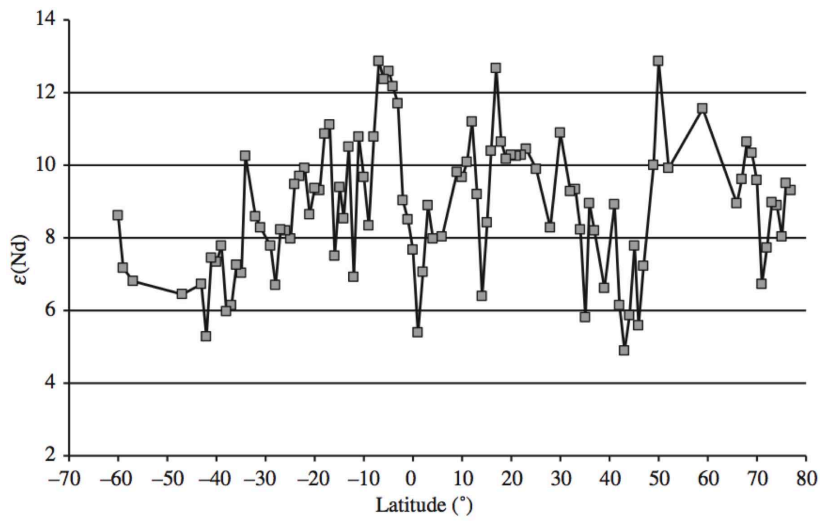

Fig. 6. Neodymium isotopic composition versus latitude (degrees north) along the Mid-Atlantic Ridge. Data have been averaged over $1^{\circ}$ intervals. $\epsilon(\mathrm{Nd})$ is the variation in ${ }^{143} \mathrm{Nd} /{ }^{144} \mathrm{Nd}$, measured in parts per 10000 . From Hofmann (2003). Copyright Elsevier Science. Reprinted with permission.
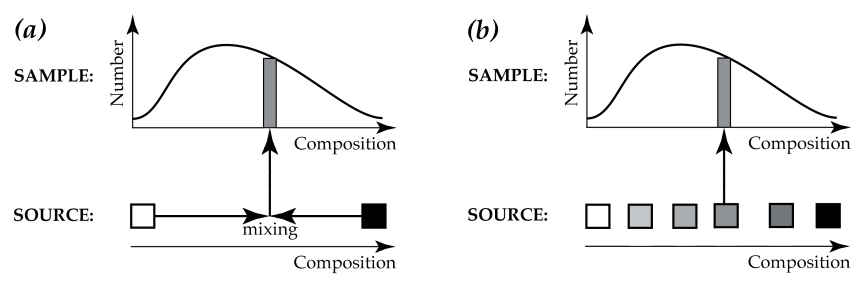

Fig. 7. Contrasting conceptions of mantle sources. (a) Generation of a sample by mixing material from two reservoirs before eruption. (b) Direct sampling of a heterogeneity of intermediate composition. From Davies (2011). Copyright Cambridge University Press. Reprinted with permission.

mantle" is thus misplaced. Instead, the more useful measure is the mean value of the distribution, as it is the mean value that governs mass balances and the amount of heat generated in the mantle, topics that will be discussed in Sect. 7.
Though a depleted end-member is ill-defined, it may still be useful to identify "enriched" end members, because they are plausibly due to the addition of material from the Earth's surface or elsewhere. However identifying an end member will elucidate a process and a source type rather than specifying the composition of a reservoir.

\subsection{Residence times}

Christensen and Hofmann (1994) obtained mean residence times of 1.3-1.6 Gyr from their numerical models of subduction, stirring and settling of oceanic crust. On the other hand Davies (2002) obtained mean residence times of 2.2-2.7 Gyr for MORBs and 2.6-3.4 Gyr for samples from the bottom accumulations of heavy tracers. Huang and Davies (2007a, b) later obtained intermediate ages from three-dimensional models.

On the one hand these results seem to demonstrate that mantle heterogeneities can plausibly survive for the order of the two billion years indicated by lead isotopes. However the discrepancies among the results were concerning. Two factors have been found to explain the discrepancies.

First, the model must be run for an appropriate time. Christensen and Hofmann's models were run for only 3.6 Gyr, and with steady convection rates. Because the mantle was likely to be hotter in the past, convection and plates would have been faster and the mantle would have been processed more rapidly. As described in Sect. 3.1, models running at present rates would need to be run for about $18 \mathrm{Gyr}$ to achieve a comparable amount of processing. Christensen and Hofmann's models fall well short of this, and in fact correspond to less than $0.5 \mathrm{Gyr}$ of the Earth's early evolution. The average residence time approaches a steady value exponentially with "model time" (analogous to the logic of Sect. 3.1 and 3.2). When converted to real "Earth time", the residence time continues to increase because of slowing convection, and its rise is shown in Fig. 8a. Even after 4.5 Gyr of Earth time, the residence time is still increasing at a significant rate. 

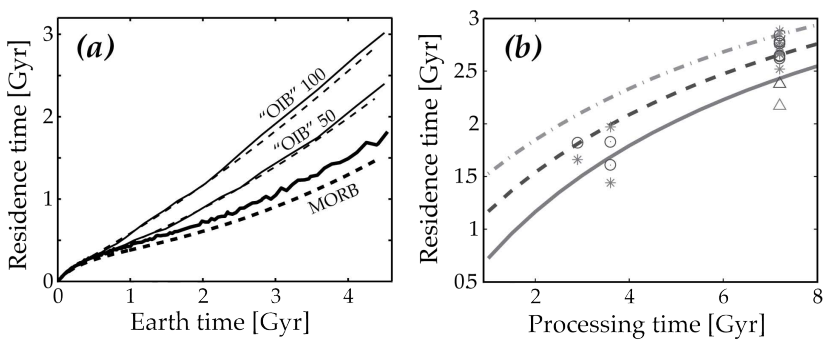

Fig. 8. (a) Residence times from MORB and "OIB" samples of three-dimensional models (solid curves). Dashed curves are estimates based on the sampling theory (Sect. 3.9). "OIB" 50 is for an excess density of $50 \mathrm{~kg} \mathrm{~m}^{-3}$, "OIB" 100 is for $100 \mathrm{~kg} \mathrm{~m}^{-3}$. (The "OIB" interpretation is discussed below.) (b) Final residence time as a function of processing time, $\tau$. Curves are from the sampling theory (Sect. 3.9) for simple sampling (solid) and two cases in which a sampling delay has been assumed (400 Myr, dashed; 1.2 Gyr, dash-dot). Results from various numerical models are indicated by the symbols. From Huang and Davies (2007b, a). Copyright American Geophysical Union.

Second, the processing time scale of the model should match the processing time scale of the mantle. It turns out that the earlier numerical models had a range of processing time scales because of different assumptions about melting depth and plate speeds. The processing time of Davies (2002) was 7.2 Gyr, whereas it was only $1.5 \mathrm{Gyr}$ in Christensen and Hofmann (1994). The relationship between the processing time and the final residence time (after $4.5 \mathrm{Gyr}$ of Earth time) can be calculated from a sampling theory outlined below, and it is shown in Fig. 8b. This shows that all the model results are reasonably consistent once the different processing times are accounted for. The processing time of the mantle was estimated (Sect. 3.1) to be about $4 \mathrm{Gyr}$, and this would predict a mean residence time of MORBs of about $1.8 \mathrm{Gyr}$.

Figure $8 \mathrm{~b}$ synthesises results from a wide range of numerical models: two dimensional and three dimensional, in rectangular or spherical geometry (including full spherical and regional spherical), at low, moderate or high Rayleigh numbers, with various viscosity structures, and steady or evolving from an early hot state. For example a higher viscosity in the lower mantle does not significantly extend residence times. An example of a 3-D spherical model with "heavy" tracers is shown in Fig. 9. Figure 8b shows that the main determinant of residence time is the processing time scale, $\tau$, defined in Sect. 3.1. Whereas the other factors can have large effects on the homogenising time scale, they have only secondary effects on the residence time. This is an important insight that makes the interpretation of mantle geochemistry more accessible.

\subsection{Sampling theory}

In Sect. 3.1 and 3.2, Eqs. (3) and (5) are derived by assuming that a particular kind of mantle material will be sampled by a MOR melting zone in proportion to the amount of that material already in the mantle. Thus for example the proportion of primitive mantle declines with time, so the rate at which primitive material melts also declines, yielding the exponential function of Eq. (3). This theoretical result is useful for interpreting numerical models, for example by confirming the numerical result that very little primitive material survived to the present (Davies, 2002). This approach has been extended in a number of ways by Huang to further elucidate the behaviour of the models, and the mantle (Huang and Davies, 2007a, b, c).

Davies (2002) found that the MORB sample of tracers had a wide range of ages from a few hundred million years to $4.5 \mathrm{Ga}$, even though the mean age was about $2.7 \mathrm{Ga}$. This result is important for interpreting noble gases, which will be discussed later. An example of a histogram of MORB ages is shown in Fig. 10.

The fraction, $f_{\mathrm{i}}$, of tracers with ages between $a_{\mathrm{i}}$ and $a_{\mathrm{i}}+\Delta a_{\mathrm{i}}$ can be derived from the sampling theory as

$f_{\mathrm{i}}=\frac{\Delta a_{\mathrm{i}}}{\tau} \exp \left(-\frac{a_{\mathrm{i}}}{\tau}\right)$

The distribution calculated from this formula is shown in Fig. 10 (solid grey line). It has the same general form as the numerical distribution, except the latter has a gap at younger ages and the rest of the histogram is slightly larger than the theoretical curve.

The absence of young tracers in the numerical distribution is plausibly due to the fact that tracers must traverse the distance from a subduction zone to a spreading center before they can be sampled. Thus the sampling is not as random as assumed implicitly in the initial sampling theory. This can be taken into account in the sampling theory by excluding the younger part of the distribution and calculating proportions of the rest in each age range. The result (Huang and Davies, 2007a) is shown in Fig. 10 as the dashed grey line, with the sampling delay adjusted to match the numerical gap. The result is an excellent fit to the numerical distribution with a theory that requires only two input parameters: the processing time, $\tau$, and the sampling delay time.

From the age distribution, the mean age can be calculated. The result, with zero delay time, is

$a_{\mathrm{tr}}=\tau\left[1-\exp \left(-t_{\mathrm{m}} / \tau\right)\right]$

where $t_{\mathrm{m}}$ is model time. The conversion to Earth time must be done for each age range before a mean is calculated. The expression with sampling delay is more complicated (Huang and Davies, 2007a). The variation of this mean age with Earth time is included in Fig. 8a (heavy dashed curve), where it follows the numerical result fairly closely. Taking account of a processing delay would reduce the discrepancy (not 


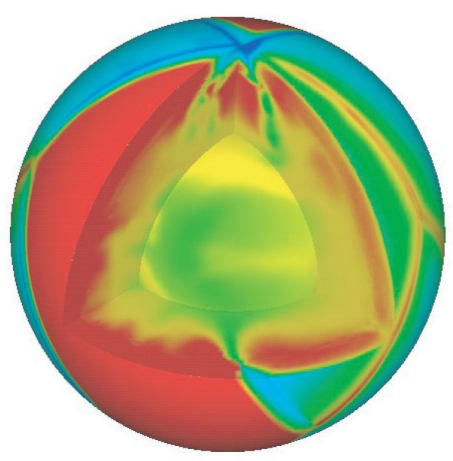

(a)

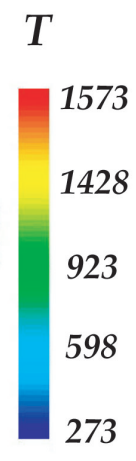

273

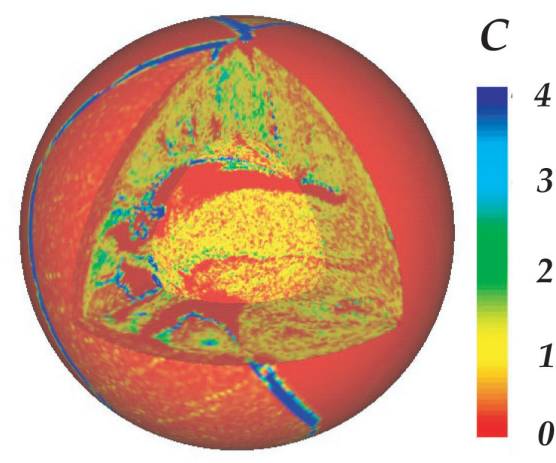

(b)

Fig. 9. Cut-away images of (a) temperature and (b) tracer concentration in a three-dimensional spherical model of mantle stirring with heavy tracers. After Huang and Davies (2007b). Copyright American Geophysical Union.

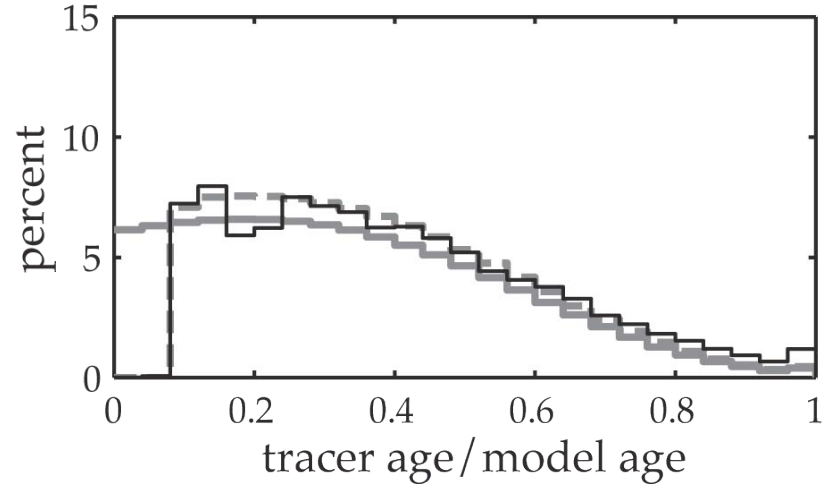

Fig. 10. Histogram of MORB tracer ages (black) compared with the age distribution predicted from the simple sampling theory (solid grey) and with a sampling delay time of $0.4 \mathrm{Gyr}$ (Earth time). The tracer ages are given relative to the final model time. After Huang and Davies (2007a). Copyright American Geophysical Union.

shown). The variation of mean age with processing time is included in Fig. 8b (solid curve). Figure $8 \mathrm{~b}$ also includes two curves that include the effect of a sampling delay of $0.4 \mathrm{Gyr}$ (dashed) and 1.2 Gyr (dash-dot). The set of theoretical curves in Fig. 8b reasonably span the results from a range of numerical models, and so confirm that the main control on the mean age is the processing time.

In models in which the tracers are "heavy", i.e. which include a small mass anomaly equivalent to the excess density of subducted oceanic crust relative to mean mantle, the mean ages of the OIB samples are larger than the MORB ages. This is presumably due to some of the heavy material being trapped, at least temporarily, in the accumulation at the bottom. The sampling theory has been extended to account for this by assuming a population of tracers that are permanently trapped (Huang and Davies, 2007b). The "OIB" sample is then taken to be a mixture of trapped tracers and freely circulating tracers. This theory involves a few more assumptions, but a plausible account can be derived. The dashed "OIB" curves in Fig. 8a are calculated from this theory for cases in which the subducted oceanic crust is 50 and $100 \mathrm{Mg} \mathrm{m}^{-3}$ denser than average mantle, and they give a good account of the numerical results.

\subsection{Processing rates that change with time}

Computer power limited some 2-D (Christensen and Hofmann, 1994) and 3-D (Huang and Davies, 2007a, b) models to low, steady Rayleigh numbers. Some such studies have included the the decrease in the depth of melting under MORs due to the cooling mantle, in 2-D (Davies, 2002) and 3-D (Huang and Davies, 2007c). More recently, evolving 2-D models have been run at full resolution for the age of the Earth (Xie and Tackley, 2004; Davies, 2008), explicitly including the slow cooling of the mantle. In these models the processing rate decreases and the processing time scale, $\tau$, increases with time.

The study by Huang and Davies (2007c) is in spherical geometry at the present mantle Rayleigh number, with significant temperature-dependence of viscosity and with more realistic plates simulated (Fig. 11), so it addresses the robustness of previous findings of stirring and processing in a more realistic manner than other studies. Huang extended the sampling theory to take account of the evolving processing time scale, which changes from $1.98 \mathrm{Gyr}$ at the beginning to $4.32 \mathrm{Gyr}$ at the end. Figure 12 shows the degree of processing and the MORB and OIB ages from this model, and from variations on the theory. The theory with variable $\tau$ fits the numerical results quite well throughout the evolution of the model. For comparison, predictions of the theory with constant $\tau$ are included, using the initial and final values.

The cumulative percentage of processed tracers is better described by the initial processing time scale, which makes sense because most of them are processed early anyway. On the other hand the final MORB and OIB ages are a little better described by the final processing time scale. In other words, 


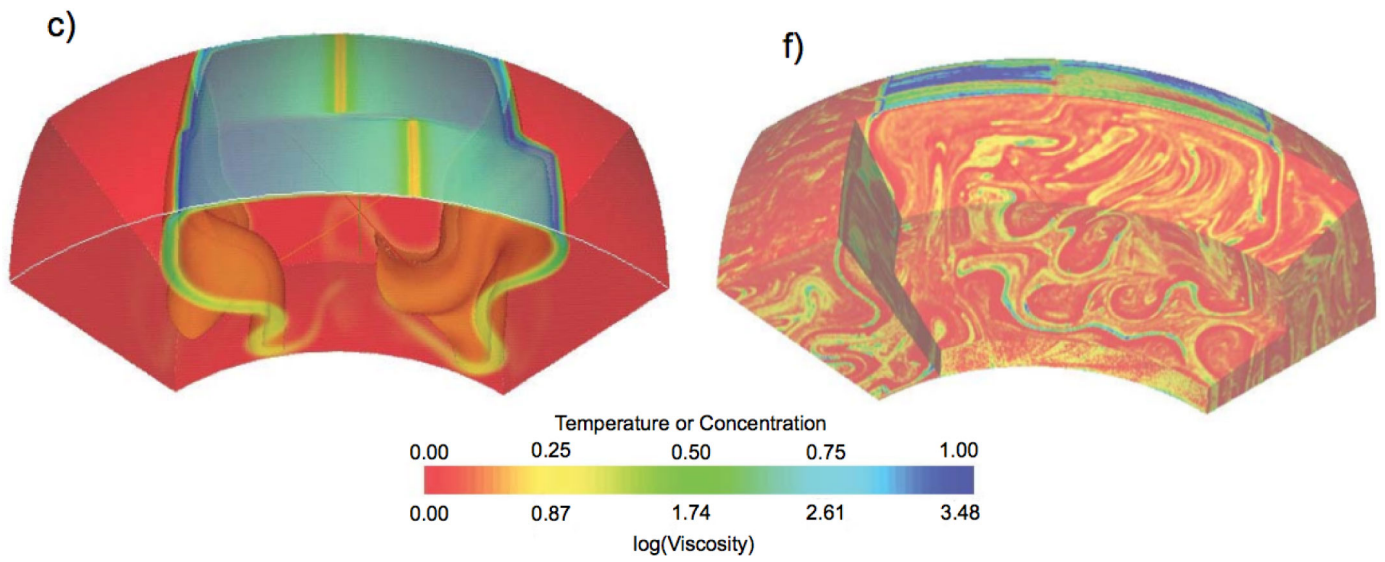

Fig. 11. Images from the three-dimensional regional model of Huang and Davies (2007c). (c) Temperature after $200 \mathrm{Myr}$ of model time, (f) tracer concentration after $18 \mathrm{Gyr}$ of model time. Copyright American Geophysical Union.

the MORB and OIB ages are controlled more by the recent processing rate than by the early processing rate.

\subsection{Conclusions, refractory elements}

The numerical models of mantle stirring are complex enough that the reasons for their behaviour are not always obvious. The value of the simplified sampling theory is that it allows the behaviour of numerical models to be understood with some confidence. The resulting insights can then be transferred to the mantle with greater confidence. For example, the concordance between numerical results and a fairly simple theory in Fig. 8b strengthens confidence in the conclusion that the main control on residence time is the processing time or, equivalently, the rate of processing through MOR melting zones.

The concordance between the resulting preferred numerical processing time and the observed lead apparent age then strengthens confidence that the numerical models are giving a reasonable representation of the mantle. All models with heavy tracers yield accumulations of tracers that settle to the bottom, supporting the Hofmann and White interpretation of the differences between MORBs and OIBs. Thus two of the primary characteristics of refractory elements and their isotopes can be reasonably accounted for by the kind of dynamical model inferred in Sect. 2, namely the difference in trace element concentrations between MORB and OIB and the apparent age of around $1.8 \mathrm{Ga}$. The question of mass balances of these elements will be taken up in Sect. 7 after melting of a heterogeneous mantle is considered in more detail.

\section{Melting in a heterogeneous mantle}

The discussions in Sect. 3 of the expectation of mantle heterogeneity, from the subduction of heterogenous lithosphere, and the observations of heterogeneity (Figs. 2, 5, 6) establish heterogeneity as a primary feature of the mantle. The heterogeneity occurs at all length scales, and it involves major elements as well as minor and trace elements and isotopes. The major-element heterogeneity is expressed as a heterogeneity of lithologies, which in the upper mantle are pyroxenite and eclogite streaks and pods in a matrix of peridotite (Ringwood, 1975; Allegre and Turcotte, 1986).

Eclogites and pyroxenites melt at lower temperatures than peridotite (Fig. 13), so as mantle rises under a mid-ocean ridge the eclogite and pyroxenite inclusions will melt first. Melt from such inclusions will be out of chemical equilibrium with the surrounding peridotite, so if it escapes it will react, and possibly refreeze (Yaxley, 2000; Spandler et al., 2008). The product of such reactions may vary from lherzolite through pyroxenite, garnet pyroxenite or even eclogite, depending on the relative proportions of melt and peridotite. For conciseness I refer to the products as hybrid pyroxenite.

Because of the back-reaction and possible freezing, the migration of melt from an eclogite pod through the peridotite matrix may be an erratic affair: some may immediately refreeze, some may remelt at a shallower level, some may combine, at shallow levels, with melt from peridotite and be erupted in that form, some may form a reaction zone that insulates later melt from reaction and allows it to travel, and even to escape to the surface, and some may remain trapped in the mantle. These possibilities are illustrated in cartoon form in Fig. 14.

For material rising under the axis of a mid-ocean ridge, these complications might not matter much, because any refrozen material would be likely to remelt at a shallower level and ultimately mix with melt from peridotite. The end product could be nearly fully equilibrated, and indistinguishable from melt from a homogenised source of the same bulk composition. 

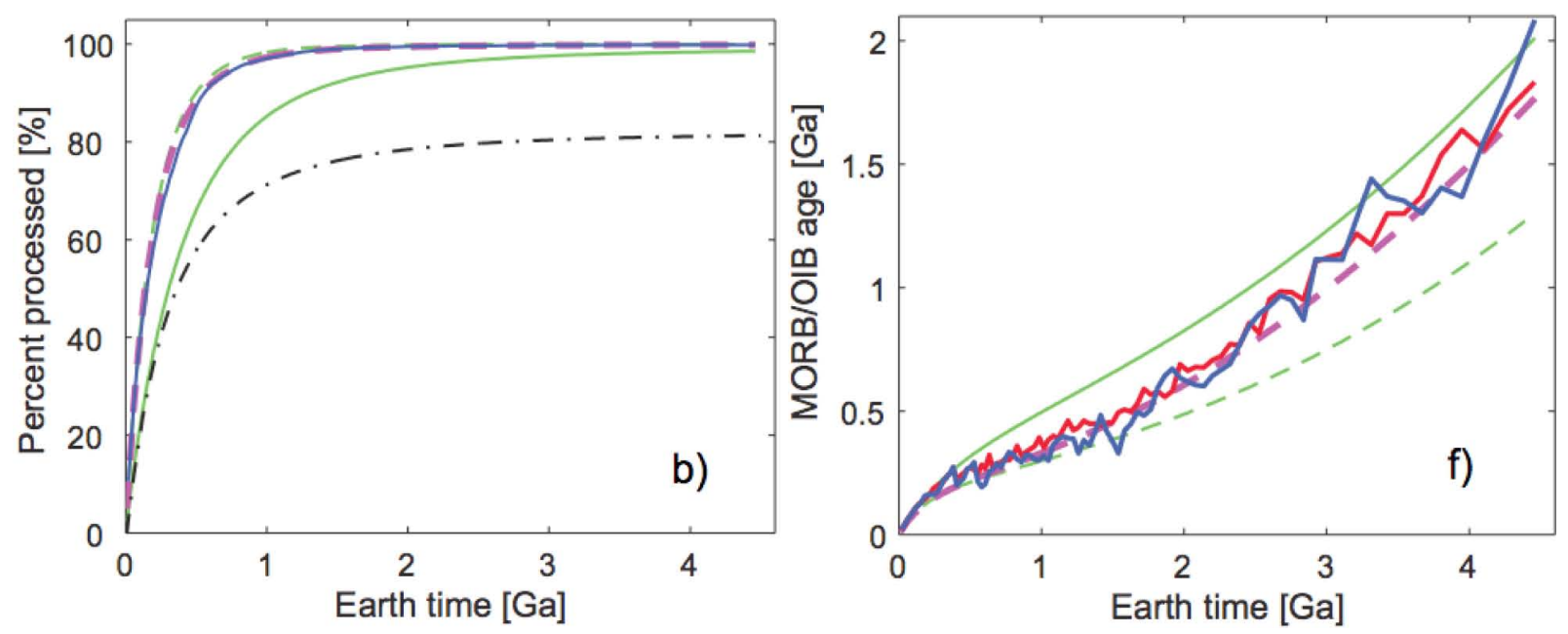

Fig. 12. Analysis of results from the model of Fig. 11. (b) Cumulative percentage of processed tracers (blue), (f) ages of MORB (blue) and OIB (red) samples. Both plots include the result from the sampling theory with variable processing time (magenta, dashed), and from the theory using constant process times: the initial processing time of $1.98 \mathrm{Gyr}$ (green, dashed) and the final processing time of $4.23 \mathrm{Gyr}$ (green, solid). The dash-dot line in (b) is the amount of degassing of ${ }^{40} \mathrm{Ar}$ relative to the total amount produced by the decay of ${ }^{40} \mathrm{~K}$.

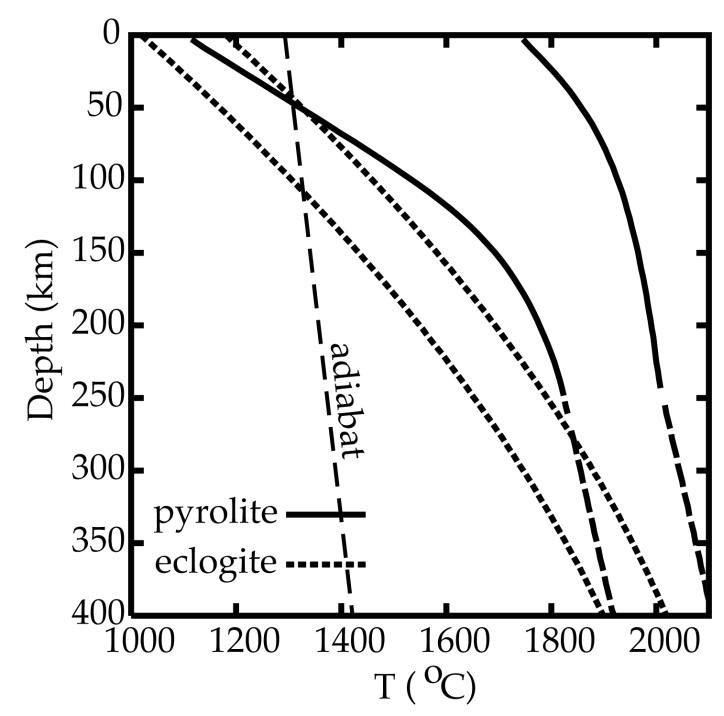

Fig. 13. Solidi (lower) and liquidi (upper) for an average mantle composition (pyrolite) and for eclogite, the upper mantle form of subducted ocean crust. An approximate solid adiabat is included. After Yasuda et al. (1994). Copyright American Geophysical Union.

However for material rising off-axis, the full range of possibilities is likely to eventuate, in some proportion or other. Thus some eclogite or pyroxenite melt might reach the surface with a recognisable signature of its source, some may homogenise with peridotite melt, and some may remain refrozen and trapped. Kogiso et al. (2004) estimate that melt from pods that are silica saturated and thicker than a few meters is likely to be able to migrate significant distances through the mantle. Evidence in MORBs and flood basalts

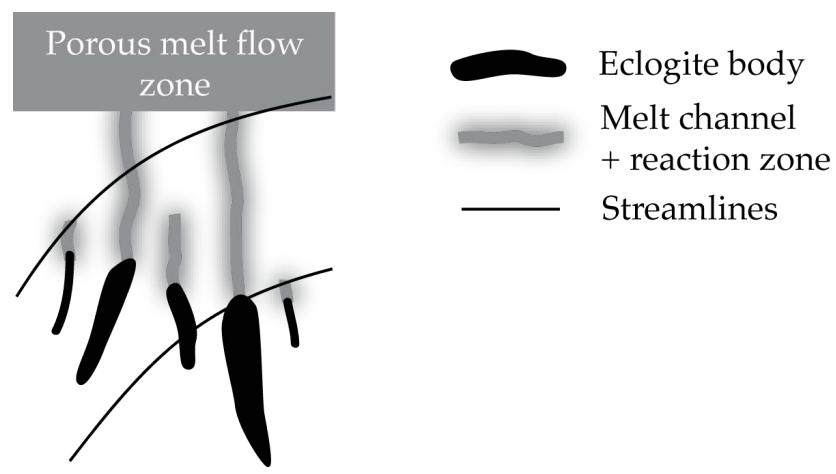

Fig. 14. Sketch of the migration of melt emerging from eclogite bodies. The melt will react with surrounding peridotite, and will tend to refreeze. Some might react completely and become trapped in the mantle, whereas other melt might migrate a significant distance and reach the peridotite melting zone. Curves suggest streamlines of the mantle flow. After Davies (2009b). Copyright American Geophysical Union.

for a contribution from eclogite or pyroxenite sources has been adduced for example by Takahashi et al. (1998) and Sobolev et al. (2005, 2007). Melt from smaller bodies and silica-undersaturated bodies is more likely to be trapped.

The greater depth of melting of eclogite and pyroxenite enhances the likelihood of melt trapping. This is clarified by comparing pictures of homogeneous and heterogeneous melting under a mid-ocean ridge. The older view of melting of a homogeneous source is illustrated in Fig. 15a. Melting begins when upwelling solid mantle reaches a depth of about $60 \mathrm{~km}$ ("Peridotite melt zone"), and it stops (or reduces to minor rates) as the mantle flow turns horizontal and the material stops decompressing. Melt generated in the melt zone 
(a)

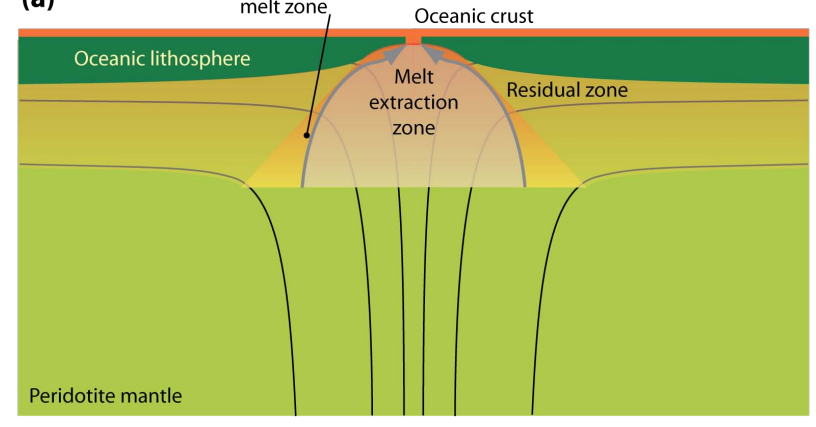

(b)

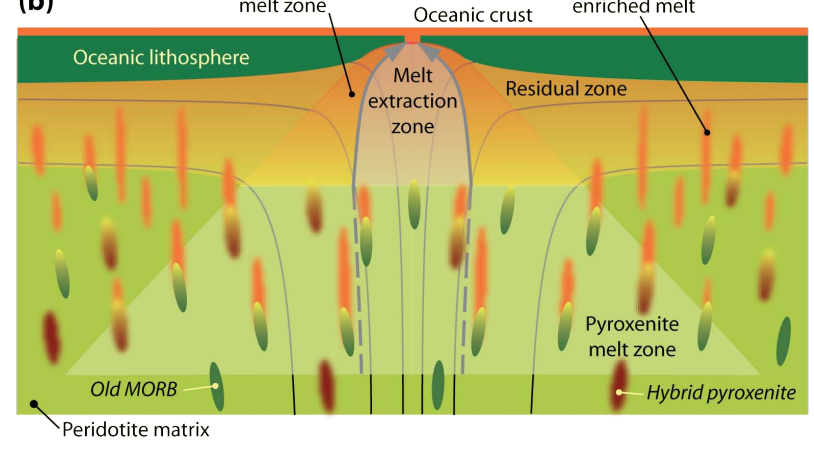

Fig. 15. Sketches of melting under a mid-ocean ridge. (a) Assuming a homogeneous source. The curves are flow lines of the solid mantle. (b) Assuming a heterogeneous source. Old subducted oceanic crust (Old MORB) in the eclogite assemblage will start melting at a greater depth than peridotite. Some of the resulting melt may fail to be extracted, and remain as hybrid pyroxenite. Multiple generations of hybrid pyroxenite may return to the melting zone. After Davies (2009b). Copyright American Geophysical Union.

is strongly focussed to the mid-ocean ridge by the low pressure induced by the diverging mantle flow (Spiegelman and Reynolds, 1999), thus defining a "Melt extraction zone".

If the mantle is heterogeneous, this picture is modified in several ways (Fig. 15b). Eclogites and hybrid pyroxenites begin to melt much deeper than peridotite, about $110 \mathrm{~km}$ (Fig. 13), so their melting zone will be much wider. Heterogeneities further from the spreading axis may not rise shallow enough to remelt, nor may they necessarily rise into the peridotite melting zone. This material may be carried away laterally without remelting (Fig. 15b). The eclogite melting that occurs outside the peridotite melting zone will tend to be in disconnected pockets. Melt from larger eclogite bodies may migrate, but much of it still may not reach the surface.

Eclogite that rises under the peridotite melt extraction zone is more likely to be extracted because the peridotite melting will tend to form a connected zone of melt within which porous flow may occur. Any eclogite melt that enters this zone is likely also to move by porous flow and to mix with the peridotite melt. The melt extraction zone may be narrower than in the homogeneous case, if the total melt productivity of the heterogeneous source is greater: the observed volume of melt, to form the $7 \mathrm{~km}$-thick oceanic crust, would by implication be drawn from a deeper, narrower zone. This would enhance the likelihood of off-axis melts being trapped. Even some off-axis peridotite melt could be trapped in this way.

The tendency of off-axis melt to be trapped will also be enhanced if the peridotite matrix is more refractory than the "fertile peridotite" usually assumed in models of the melting of a homogeneous source. This is because the refractory peridotite melting would begin shallower than $60 \mathrm{~km}$ and over a narrower width, and so be even less likely to capture the pyroxenite products.

Thus significant amounts of hybrid pyroxenite are likely to be trapped, and then recirculated within the mantle. Over time some of it will return to MORB melting zones, potentially to be remelted. Thus there will be multiple generations of hybrid pyroxenite, and a significant population of it may accumulate, as foreshadowed in Sect. 3.2. The material entering melting zones will then have three main components, not two: peridotite residue, subducted oceanic crust and hybrid pyroxenite. Incompatible elements will be carried by both the subducted oceanic crust and the hybrid pyroxenite. The two types of heterogeneous inclusion are depicted schematically in Fig. 15b.

Two fundamental implications follow from this picture. One is, as already stated, incompatible elements will over time become concentrated in the heterogeneous inclusions, i.e. the subducted oceanic crust and the hybrid pyroxenite. The other is that the bulk extraction of incompatible elements will not be governed only, or even mainly, by local chemical partition coefficients. These points will be briefly elaborated.

The Earth is expected to have formed hot, due to the release of gravitational energy of accretion, and especially the hypothesised moon-forming giant impact, which may have melted most or all of the Earth (Melosh, 1990). A magma ocean would have cooled to a stiff mush within only tens of thousands of years, though large impacts would reform magma lakes frequently (Davies, 1990a). Although a lot of melting would have taken place, the liquid and solid mantle regimes would have been highly dynamic, and competing mixing processes would have tended to prevent major differentiation and stratification of the mantle (Stevenson, 1990). The difficulty of finding more than a vestige surviving from such differentiation provides some evidence for this claim. The result of this early history is thus likely to have been a mantle that had undergone melting and that had been vigorously stirred but not completely homogenised. The melt products from the early mantle would have been broadly mafic (basaltic through komatiitic). In other words, a heterogeneous mantle, more or less like the present, may date from very early in Earth history. There is accumulating evidence for significant isotopic heterogeneity in the earliest Archean and the Hadean that supports this expectation (Harper and Jacobsen, 1992; Harrison et al., 2005; Valley, 2006; Bennett et al., 2007; Blichert-Toft and Albarède, 2008; O'Neil et al., 
2008), though there is debate about the degree of heterogeneity (Kemp et al., 2010).

Consequently we could expect the mantle's incompatible elements to have been concentrated into mafic mantle heterogeneities from quite early in Earth history. The peridotitic matrix surrounding the heterogeneities would be correspondingly depleted and refractory.

On the second implication of heterogeneity, which factors control element extraction, the residue from melting under mid-ocean ridges has commonly been inferred to be strongly depleted of incompatible elements, on the assumption that incompatible elements are efficiently stripped from solid phases and carried away by the melt. This may be true locally within the melting zone, but if the melt does not efficiently migrate to the surface (Fig. 14) then the incompatible elements will not be efficiently removed from the melt zone. This is the picture already argued above (Fig. 15). The implication is that significant quantities of incompatible elements may remain in the residue zone.

A simple illustration makes the point that the retention of incompatibles is probably not governed by chemical equilibrium partitioning. If an element has a partition coefficient of 0.01 , then only about $1 \%$ of it will remain in the solid phase, and $99 \%$ will partition into the melt. However if only $1 \%$ of that melt fails to migrate out of the residue zone, then the amount of the incompatible element remaining in the residue zone will be doubled. If several percent of melt remain trapped, then the bulk abundance of the incompatible element will be several times that predicted by chemical equilibrium partitioning. The abundance will be governed instead by the vagaries of melt migration through a heterogeneous medium, in other words by a combined physical-chemical, dynamical and probably disequilibrium process rather than by pure chemical equilibrium.

The incompatibilities inferred from the composition of oceanic crust may not be greatly affected by this retention, because only a few percent of the incompatible elements may be involved.

These two implications will be explored further in the rest of this review. They provide a plausible location for noble gases in the mantle, and they require a re-evaluation of the MORB source composition, the mass balances of incompatible elements and the heating of the mantle.

\section{Noble gases in the heterogeneous mantle}

The place of noble gases in the mantle was until recently quite enigmatic. They did not fit easily into any version of mantle structure or dynamics. One problem was that the samples that show the most primitive (unradiogenic) noble gas characteristics are depleted relative to chondritic, which implied they had been processed through a melting zone yet had retained or regained primitive noble gas. It is now evident that the samples with more primitive noble gases have the $\mathrm{Nd}$, $\mathrm{Hf}$ and $\mathrm{Pb}$ character of the non-chondritic primitive mantle implied by ${ }^{142} \mathrm{Nd}$, which would resolve this problem (Caro and Bourdon, 2010; Jackson et al., 2010).

A second problem has been the location of noble gases in the mantle, so it has been difficult to understand why some OIBs contain very unradiogenic $\mathrm{He}, \mathrm{Ne}$ and $\mathrm{Ar}$, let alone to develop a quantitative understanding of the evolution and present character of noble gases analogous to that for refractory elements (Sect. 3). The heterogeneous mantle discussed in the previous section offers a straightforward and quantifiable explanation of the evolution and present character noble gas observations, as will be discussed below.

A third problem has been the mass balance of ${ }^{40} \mathrm{Ar}$, whereby some of the ${ }^{40} \mathrm{Ar}$ that should have been generated through Earth history seemed to be missing (Allegre et al., 1996). This problem is considerably relieved by the nonchondritic Earth, which implies less ${ }^{40} \mathrm{Ar}$ would have been generated (Boyet and Carlson, 2005), and any remaining discrepancy can be accommodated by the recognition that previous estimates of the MORB source composition yield lower bounds on incompatibles, as discussed in Sects. 3 and 4. The full accounting for heterogeneity just discussed could plausibly accommodate even the chondritic estimates when all uncertainties are taken into account (Davies, 2010). This will be explored in Sect. 7.

Many aspects of the noble gases can be illustrated by helium, so it is the only one that will be considered in detail here, except for the mass balance of ${ }^{40} \mathrm{Ar}$. The earlier interpretations and debates regarding the noble gases have been presented before (Allegre et al., 1987; Porcelli and Wasserburg, 1995b; Class and Goldstein, 2005; Tolstikhin and Hofmann, 2005; Parman, 2007; Albarède, 2008), and will not be canvassed at length here.

Isotopic observations of helium are summarised in Fig. 16, with observations of strontium and lead for comparison. Helium ratios as high as $50 R_{\mathrm{A}}$ have subsequently been found (Stuart et al., 2003; Starkey et al., 2009). The helium distribution needs to be interpreted in the light of the discussion (Sect. 3.7) of sampling a heterogeneous source, in other words without assuming mixing between large reservoirs. All three data sets show that MORBs have a narrower range than OIBs. All distributions are skewed, with relatively long tails on one side. For $\mathrm{Sr}$ and $\mathrm{Pb}$ the OIBs tend to have more radiogenic ratios, but overlapping the MORB range. Helium, on the other hand, tends to be less radiogenic, though some values are more radiogenic. (Unfortunately the convention for $\mathrm{He}$ is to put the radiogenic isotope in the denominator, contrary to that for other elements.)

The main difference between helium in OIBs and MORBs is the much greater range of ratios in OIBs -5-6 times bigger than for MORBs. For $\mathrm{Sr}$ and $\mathrm{Pb}$ the ranges differ by only a factor of 2 or so. A second difference in all three systems is that the OIB means differ from the MORB means. In the case of $\mathrm{He}$, the difference is less than a factor of two. 

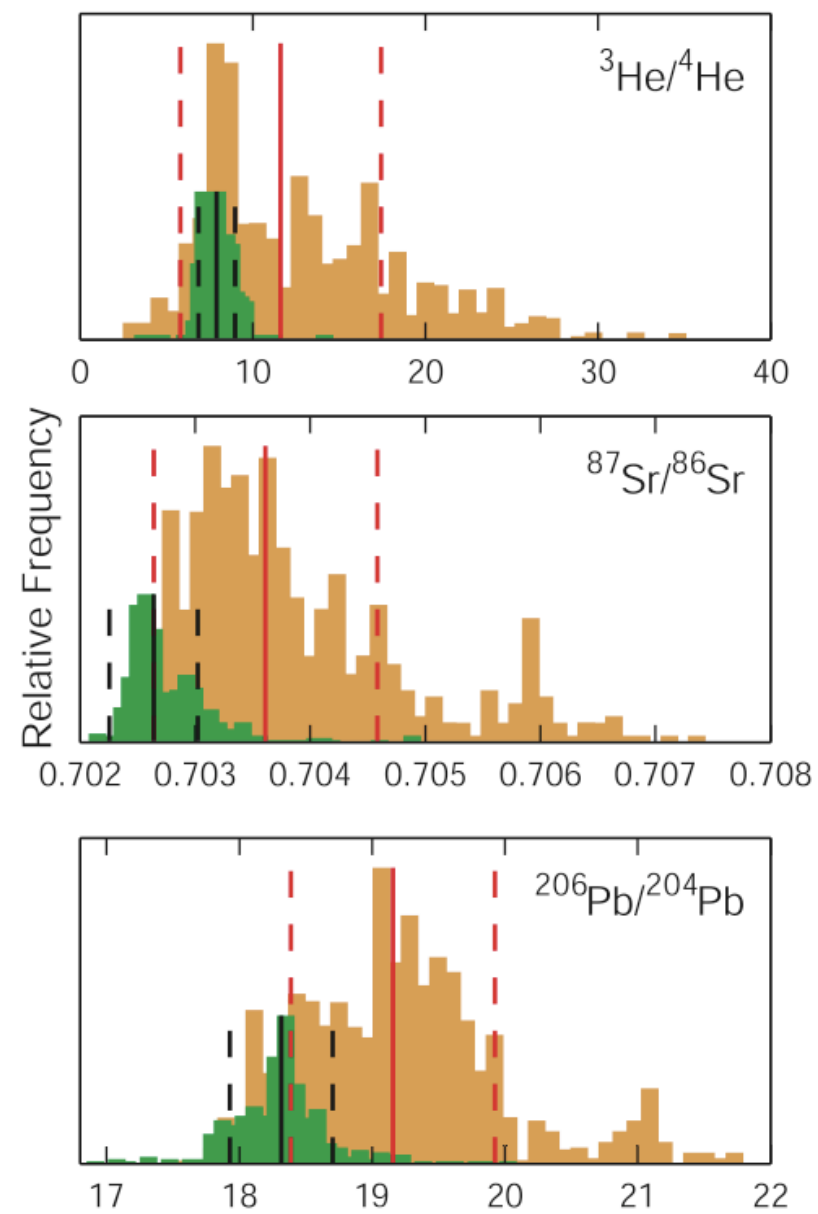

Fig. 16. Histograms of isotopic ratios observed in MORB (green) and OIB (yellow). Helium is normalised to the atmospheric ratio, $R_{\mathrm{A}}=1.4 \times 10^{-6}$. Dashed lines mark \pm one standard deviation about the medians (solid lines). ${ }^{3} \mathrm{He} /{ }^{4} \mathrm{He}$ values for MORB and OIB are $7.92 \pm 1.06 R_{\mathrm{A}}$ and $11.62 \pm 5.82 R_{\mathrm{A}}$, respectively; ${ }^{87} \mathrm{Sr} /{ }^{86} \mathrm{Sr}$ values are $0.7026 \pm 0.0004$ and $0.7036 \pm 0.0010$; ${ }^{206} \mathrm{~Pb} /{ }^{204} \mathrm{~Pb}$ values are $18.32 \pm 0.39$ and $19.16 \pm 0.77$. After Ito and Mahoney (2006). Copyright American Geophysical Union.

The least radiogenic helium is associated with $\mathrm{Sr}, \mathrm{Nd}$ and $\mathrm{Pb}$ isotopes corresponding to relative depletion of incompatible elements. A recent depiction of this is shown in Fig. 17a (Class and Goldstein, 2005). The inference from ${ }^{142} \mathrm{Nd}$ that the primitive mantle may itself have been depleted relative to chondrites (Boyet and Carlson, 2005) has led to the plausible identification of a mantle component that is consistently primitive in both noble gas and refractory element isotopes. Figure $17 \mathrm{~b}$ shows that the least radiogenic helium is associated with the inferred non-chondritic primitive ${ }^{143} \mathrm{Nd} /{ }^{144} \mathrm{Nd}$ (Caro and Bourdon, 2010), and analogous associations occur for strontium and lead (Jackson et al., 2010).
Almost all previous discussions of the helium isotopes have focussed great attention on the highest value of ${ }^{3} \mathrm{He} /{ }^{4} \mathrm{He}$, reflecting an implicit assumption that distinct reservoirs must be involved (Sect. 3.7, Fig. 7a). However if the observed distribution merely reflects a distribution of values in a heterogeneous source (Fig. 7b), then the extreme values do not imply reservoirs.

So, the question is not how to fit a primitive, undegassed reservoir into the dynamic mantle. Rather, one question is whether it is plausible that a relatively primitive signal can still be detected. A second question is how two populations of noble gases can arise that have somewhat different isotopic means and spreads. Straightforward answers suggest themselves from the discussion of heterogeneous melting in the previous Section.

From the previous discussion we can distinguish two kinds of recycling of mantle material (Fig. 18a). The formation of oceanic crust, from melt under a mid-ocean ridge, extracts mafic material from the mantle, and subduction then returns that material to be stirred into the mantle. While it is at the surface, in the form of oceanic crust, its complement of noble gases will be lost, by degassing. On the other hand its complement of refractory trace elements will largely be retained, though it may be modified to some degree. We may call this external recycling. (Hofmann has long emphasised that geochemically oceanic crust is part of the dynamic mantle system, rather than analogous to continental crust (Hofmann, 1988, 1997).) On the other hand hybrid pyroxenite, also formed by melting under a mid-ocean ridge, will recirculate internally. Because it does not erupt to the surface, it will not degas. Thus any complement of noble gases it has will be preserved.

It was argued in Sect. 4 that mantle heterogeneity, including subducted mafic crust and hybrid pyroxenite, will have originated early in Earth history. This implies that successive generations of both materials will have formed. As such materials are carried into a MOR melting zone, it is plausible that their melts will mix to a significant degree, so that melt from subducted oceanic crust, previously degassed, will regain some noble gases. Some of the resulting melt mixture will erupt and degas, so that part of the complement of noble gases will be lost. The remaining melt mixture will be trapped, forming a new generation of hybrid pyroxenite that will contain the balance of the noble gases that entered the melting zone. In this way the noble gases will come to reside in the hybrid pyroxenite component of the mantle.

A key point then follows, that the composition of hybrid pyroxenite will be intermediate between the compositions of the peridotite matrix and subducted oceanic crust. Because the oceanic crust is denser than average mantle through much of the depth of the mantle (Yasuda et al., 1994), so will the hybrid pyroxenite, or at least some of it. Thus we would expect some hybrid pyroxenite to settle into the $\mathrm{D}^{\prime \prime}$ at the base of the mantle, as does some subducted oceanic crust in numerical models (Figs. 4 and 9). Thus the $\mathrm{D}^{\prime \prime}$ region would 

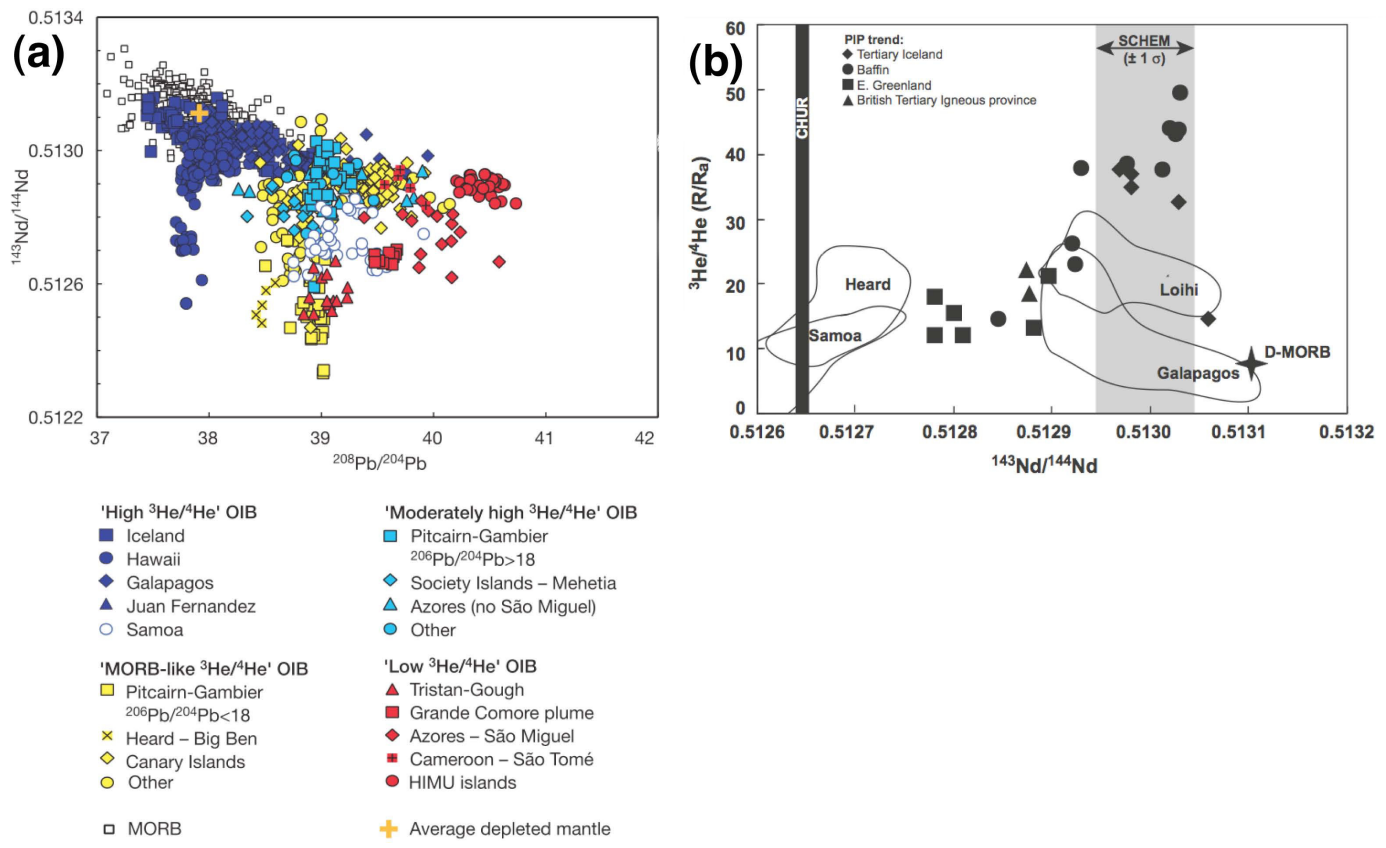

Fig. 17. $\mathrm{Nd}-\mathrm{Pb}-\mathrm{He}$ isotopes of OIB and MORB. (a) High ${ }^{3} \mathrm{He} /{ }^{4} \mathrm{He}$ OIB have the relatively a depleted $\mathrm{Nd}$ signal and low $\mathrm{Pb}$ isotope ratios. From Class and Goldstein (2005). Reprinted from Nature with permission. Copyright Macmillan Magazines Ltd. (b) The highest ${ }^{3} \mathrm{He} /{ }^{4} \mathrm{He}$ are associated with Nd isotopes corresponding to the "super-chondritic Earth model" (SCHEM) inferred from ${ }^{142} \mathrm{Nd}$ isotopes, and thus inferred to be primitive. From Caro and Bourdon (2010). Copyright Elsevier Science. Reprinted with permission.
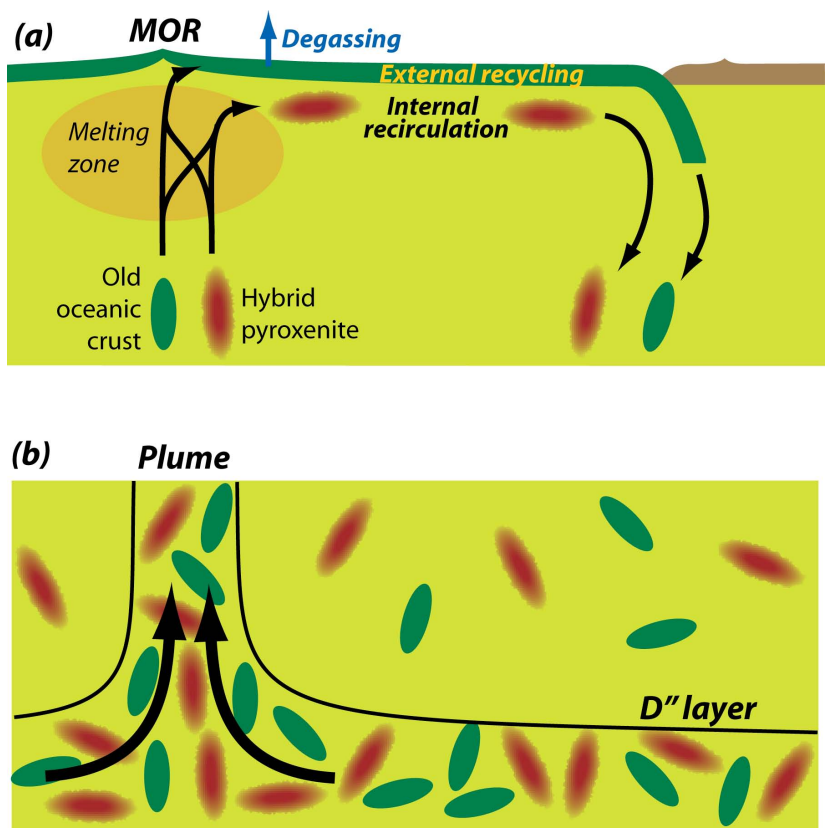

Fig. 18. Recycling through the mantle. (a) formation of oceanic crust, which degasses, and formation of hybrid pyroxenite, which does not degas. (b) Both old subducted oceanic crust and hybrid pyroxenite are denser than average mantle and would tend to accumulate in the $\mathrm{D}^{\prime \prime}$ region, where they might be sampled by mantle plumes. accumulate a mixture of subducted oceanic crust and hybrid pyroxenite (Fig. 18b).

As described in Sect. 2, mantle plumes are expected to entrain material from the $\mathrm{D}^{\prime \prime}$ accumulations and deliver it to volcanic hotspots, at which OIBs are erupted. Thus OIBs would be expected to contain the signatures both of externally recycled, degassed oceanic crust and of internally recycled, gassy hybrid pyroxenite. The spread of helium isotopic ratios in OIBs, ranging from less radiogenic to more radiogenic than in MORBs, would thereby be accounted for.

However this does not yet explain the much greater isotopic spread in OIBs compared with MORBs, particularly those samples with very unradiogenic helium (Fig. 16). Numerical models of recycling of oceanic crust have already demonstrated that material in the $\mathrm{D}^{\prime \prime}$ accumulations has a longer residence time than material circulating in the body of the mantle (Sect. 3.8). Thus we would expect that hybrid pyroxenite from $\mathrm{D}^{\prime \prime}$ would rise into the MOR melting zones less often, so it would degas more slowly. We could thus expect that it would have a higher content of primordial ${ }^{3} \mathrm{He}$ than hybrid pyroxenite circulating in the body of the mantle. This could explain the occurrence of higher ${ }^{3} \mathrm{He} /{ }^{4} \mathrm{He}$ ratios in some OIBs. It might even provide for some remaining material that is essentially primitive.

These qualitative conclusions can be quantified with the same approach used in Sect. 3.1 and 3.2 to estimate the fraction of remaining primitive material and the amount of subducted oceanic crust still in the mantle. In other words the 
evolution of noble gases can be calculated in terms of the model time, $t_{\mathrm{m}}$, relative to which convection proceeds at a steady rate. The rate of degassing is proportional to the rate of processing through the melting zone and to the amount of gas remaining in the mantle. Thus the amount of ${ }^{3} \mathrm{He}$ in the mantle will decline exponentially relative to model time, as in Eq. (3), though much of the ${ }^{3} \mathrm{He}$ will reside in hybrid pyroxenite rather than in the small remaining primitive fraction. The amount of ${ }^{4} \mathrm{He}$ is determined by a competition between the same degassing process and its generation from radioactive uranium and thorium.

An indicative calculation was presented by Davies (2010). The initial abundance of ${ }^{3} \mathrm{He}$ was estimated by projecting exponentially backwards in time from the present abundance. The present abundances used were the "Medium gas" case of Davies (2010), shown in Table 1. The hypothetical undegassed lower mantle case is included for comparison. Conventional estimates of noble gas abundances are based on the observed helium flux from mid-ocean ridges (Farley et al., 1995). Davies cited several arguments that actual abundances may be higher than conventional estimates, including the implication of heterogeneous melting that only part of the mantle complement would emerge at MORs, so that abundances of incompatible elements may be substantially higher than conventional estimates. However the absolute abundances of the noble gases makes little difference to the evolution to be illustrated here, and is most relevant to the mass balance of argon, to be discussed later.

Returning to the indicative calculation of helium evolution, it is necessary to allow for a period of faster degassing within the first 0.5-1 Gyr of Earth history, which corresponds to a period of rapid mantle cooling from an initial hot state (Davies, 1993). Faster degassing has previously been inferred from argon and xenon observations (Allegre et al., 1987; Turner, 1989; Tolstikhin et al., 2006). The evolution of ${ }^{4} \mathrm{He}$ is then calculated from the abundances of $\mathrm{U}$ and $\mathrm{Th}$ through time and the degassing inferred from ${ }^{3} \mathrm{He}$.

There is debate about the initial abundances of the nonnucleogenic noble gas isotopes in the solid Earth. McDougall and Honda infer early abundances one hundred to one thousand times their present values (McDougall and Honda, 1998). Tolstikhin et al. (2006) note that different assumptions about the formation process of the Earth can lead to widely different estimates. There is also great uncertainty about the rate of mantle overturning during and soon after the formation of the Earth. Thus the present calculations can have little to say about the earliest times, and they are most useful for the period after the early transient cooling, from roughly $4 \mathrm{Ga}$.

Results of the calculations are shown in Fig. 19. The MORB curves are calculated using a residence time of $1.5 \mathrm{Gyr}$, as indicated by a numerical convection model of Davies (2008), illustrated in Fig. 4. The unradiogenic OIB curves assume a residence time 2.5 times this, consistent with
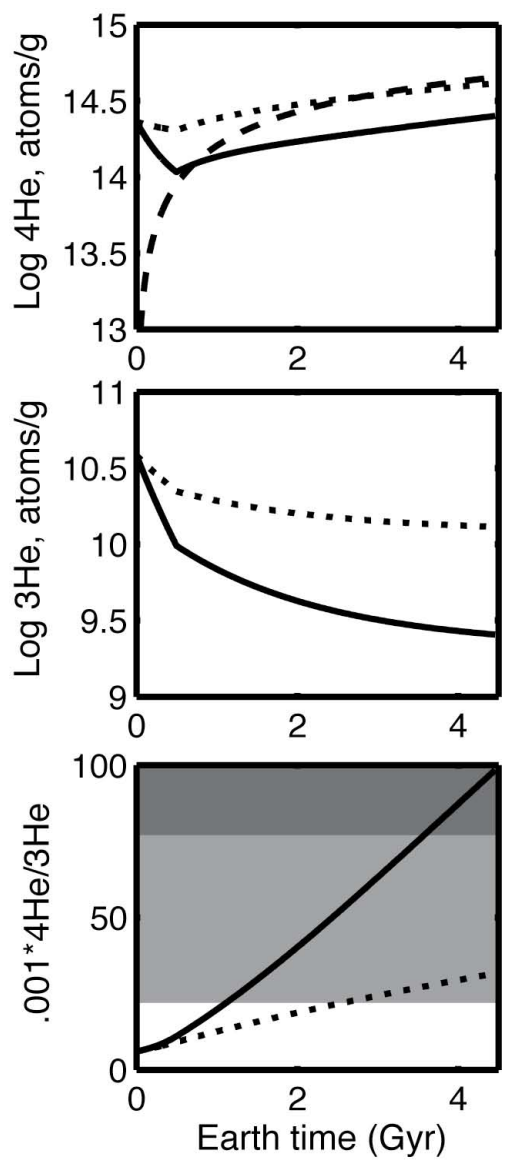

Fig. 19. An indicative calculated evolution of helium isotope concentrations and ratios. MORB source: solid curves; unradiogenic OIB source: short-dashed; radiogenic production: long-dashed. The degassing rate is assumed to have been 3 times higher during the first 0.5 Gyr. Dark grey: observed MORB range; light grey: observed OIB range. The MORB source calculation assumes a residence time of about $1.5 \mathrm{Gyr}$, whereas the unradiogenic OIB source residence time is assumed to be 2.5 times greater, i.e. about 3.75 Gyr. From Davies (2010). Copyright American Geophysical Union.

some of the older components of the $\mathrm{D}^{\prime \prime}$ region in that numerical model (Fig. 10).

The key result is that the calculated present isotopic ratios span the observed range (Fig. 16). The median MORB ${ }^{3} \mathrm{He} /{ }^{4} \mathrm{He}$ of about $8 R_{\mathrm{A}}$ corresponds to a ${ }^{4} \mathrm{He} /{ }^{3} \mathrm{He}$ ratio of about 90000 . The less radiogenic OIB ${ }^{3} \mathrm{He} /{ }^{4} \mathrm{He}$ of about $35 \mathrm{R}_{\mathrm{A}}$ corresponds to a ${ }^{4} \mathrm{He} /{ }^{3} \mathrm{He}$ ratio of about 20000 . (The rarest, least radiogenic ratio of $50 R_{\mathrm{A}}$ corresponds to ${ }^{4} \mathrm{He} /{ }^{3} \mathrm{He}$ of about 14000$)$. The mean $\mathrm{D}^{\prime \prime}$ age in the Davies numerical model is about $2.5 \mathrm{Ga}$, and using this residence time in the present calculation yields a ${ }^{4} \mathrm{He} /{ }^{\beta} \mathrm{He}$ ratio of about 45000 , compared with observed median $\mathrm{OIB}{ }^{4} \mathrm{He} /{ }^{\beta} \mathrm{He}$ ratio of about $60000\left({ }^{3} \mathrm{He} /{ }^{4} \mathrm{He}\right.$ of about $\left.11.6 R_{\mathrm{A}}\right)$. 
Table 1. Noble gas abundances.

\begin{tabular}{|c|c|c|c|c|c|c|}
\hline & $\begin{array}{l}{ }^{4} \mathrm{He} \\
\left(10^{13}\right)\end{array}$ & $\begin{array}{l}{ }^{3} \mathrm{He} \\
\left(10^{8}\right)\end{array}$ & $\begin{array}{l}{ }^{21} \mathrm{Ne} \\
\left(10^{6}\right)\end{array}$ & $\begin{array}{l}{ }^{22} \mathrm{Ne} \\
\left(10^{8}\right)\end{array}$ & $\begin{array}{l}{ }^{40} \mathrm{Ar} \\
\left(10^{13}\right)\end{array}$ & $\begin{array}{l}{ }^{36} \mathrm{Ar} \\
\left(10^{8}\right)\end{array}$ \\
\hline \multicolumn{7}{|c|}{ (a) Conventional estimates, MORB source } \\
\hline Low gas & $\begin{array}{l}7 \\
(5-9)\end{array}$ & $\begin{array}{l}8 \\
(6-10)\end{array}$ & $\begin{array}{l}6 \\
(4-8)\end{array}$ & $\begin{array}{l}0.9 \\
(0.6-1.1)\end{array}$ & $\begin{array}{l}2 \\
(0.5-3)\end{array}$ & $\begin{array}{l}7 \\
(2-10)\end{array}$ \\
\hline \multicolumn{7}{|l|}{ (b) New estimates, MORB source } \\
\hline Medium gas & 14 & 16 & 12 & 1.8 & 15 & $\sim 30 ?$ \\
\hline High gas & 20 & 24 & 18 & 3 & 22 & $\sim 70 ?$ \\
\hline \multicolumn{7}{|l|}{$\begin{array}{l}\text { (c) "Undegassed lower mantle" } \\
\text { Porcelli and Wasserburg (1995a) }\end{array}$} \\
\hline & 100 & 500 & 570 & 150 & 56 & 600 \\
\hline
\end{tabular}

Abundances in atoms per gram. (Plausible ranges in parentheses.)

To be clear that this is not circular logic, the simplified degassing history, including the early faster degassing, is constrained by the need to match the present MORB isotopic ratio, but the OIB ratios are then obtained using the independent residence time estimates from a numerical convection model. Thus the MORB-source calculation demonstrates the ability of this model to accommodate the observations, and the OIB-source calculations constitute in independent test of it.

Adding confidence to these results is that fact that the observations of neon and argon isotopic ratios can be accounted for in the same calculations with no additional assumptions (Davies, 2010).

The xenon isotopes ${ }^{129} \mathrm{Xe}$ and ${ }^{136} \mathrm{Xe}$ have a higher relative abundance in the mantle than in the atmosphere (McDougall and Honda, 1998), but no difference has been resolved between MORBs and OIBs, so analogous information about the internal structure of the mantle is not directly implied. However different early degassing timescales have been deduced. The ${ }^{129} \mathrm{Xe}$ anomaly requires early degassing of the mantle, within a few half lives of its parent ${ }^{129} \mathrm{I}(15.7 \mathrm{Myr})$ (Allegre et al., 1987). The ${ }^{136} \mathrm{Xe}$ is produced by decay of both ${ }^{244} \mathrm{Pu}$ (half life $80 \mathrm{Myr}$ ) and ${ }^{238} \mathrm{U}$ (half life $4.47 \mathrm{Gyr}$ ). Tolstikhin et al. (2006), by comparing these three Xe isotopes, have inferred the presence of a very rapidly degassed reservoir whose degassing closed at around $4.47 \mathrm{Ga}$, and a longer rapid degassing phase of the rest of the mantle, closing at around $4 \mathrm{Ga}$. The present degassing calculations do not apply to such early stages. However numerical models like that in Fig. 4 (Davies, 2008) show that a small amount of material from the earliest history of the Earth is likely still to persist in $\mathrm{D}^{\prime \prime}$.

The above results indicate that the observations of noble gases in the mantle can be accommodated by the heterogeneous mantle discussed above. The gases are likely to be carried in hybrid pyroxenite. They would degas rather slowly from the mantle because they would only be partially de- gassed at mid-ocean ridges, the remaining gas recirculating in the hybrid pyroxenite formed from trapped melt. They would degas even more slowly from the $\mathrm{D}^{\prime \prime}$ accumulation because of the longer residence times of $\mathrm{D}^{\prime \prime}$ material. This difference in residence times is enough to account for the greater proportion of the "primordial" isotopes that is observed in some ocean island basalts. The persistence in numerical models of some ancient material in $\mathrm{D}^{\prime \prime}$ is consistent with the recent detection of isotopic signals (in $\mathrm{He}, \mathrm{Nd}$ and $\mathrm{Pb}$ ) that are plausibly close to primitive.

\section{Average MORB source depletion: DMM is an upper bound}

Traditional models, assuming a strongly depleted MORB source and a chondritic bulk Earth composition, fail to account for abundances of the incompatible trace elements without assuming a hidden layer that is much less depleted than the presumed MORB source, as discussed in the Introduction. Both assumptions have now been questioned.

The evidence from ${ }^{142} \mathrm{Nd}$ that the accessible silicate Earth is more depleted than the chondritic meteorites could imply a hidden, enriched reservoir that ensures a mean chondritic composition (Carlson and Boyet, 2008), but the geophysical evidence summarised in Sect. 2 precludes such a reservoir (as will be elaborated in Sect. 7). If the bulk Earth is more depleted than chondritic then the need for a hidden layer is reduced, and possibly eliminated (Boyet and Carlson, 2005).

Regardless of the bulk Earth composition, previous estimates of mantle composition, which seem almost universally to have been based on a "depleted MORB mantle" (DMM) concept, do not take proper account of the implications of mantle heterogeneity. When inappropriate assumptions are discarded it can be seen that the DMM gives a lower bound on the incompatible element content. The mean content must be higher, and might even be high enough to accommodate a 
chondritic Earth, should that not be precluded by the ${ }^{142} \mathrm{Nd}$ evidence.

The discussion of heterogeneity in Sect. 4 showed it is likely that a larger proportion of incompatible elements remains in the residue of MOR melt zones than is predicted by assuming equilibrium melting of a homogeneous source. Other arguments will now be presented that lead to the same conclusion.

To avoid confusion, it is essential to bear in mind the distinction between the putative "depleted MORB mantle" and the actual MORB source. The goal of the present discussion is to estimate the composition of the source of mid-ocean ridge basalts - all of them, of whatever affinity and composition. In other words the "MORB source", as use here, refers to whatever a mid-ocean ridge happens to sample.

\subsection{Focus on a putative "depleted" end member}

Most discussions of the MORB source composition focus on something called the depleted MORB source or the depleted mantle. To deduce its composition the discussions usually focus on something called "normal MORB". However the definition of "normal" MORB has never been clear, and it has usually been circular: "normal" MORB is MORB that is not abnormal (Davies, 1984). The reason is that there is no clear demarcation between "normal" MORB and "enriched" MORB or other alleged varieties, a point more recently stressed also by Hofmann (2003). The distributions of compositions are not bimodal. Rather, there is a single distribution of MORB composition, with a long tail on the enriched side, as is indicated in Fig. 16 (histograms like this are not easy to find, a reflection perhaps of the lack of recognition of the issue). Various demarcations of normal MORB (nMORB) seem to be used, such as that it does not come from an unusually shallow ridge crest, that it does not contain an "obviously" enriched signature, that is it not too close to a hotspot, or that it is the most common composition of the distribution (the mode, in statistical terms). However none of these criteria prescribes a clear-cut boundary.

The problem is emphasised by Hofmann (2003) using the lanthanum/samarium ratio shown in Fig. 20. According to Hofmann nMORB is often defined as having normalised $\mathrm{La} / \mathrm{Sm}<1$, yet this distribution is quite continuous across that value. Furthermore, an estimate of the mean concentration of La based on that criterion would be seriously in error, because it would exclude the more enriched end of the distribution in which most of the La resides.

The underlying problem here is the implicit assumption that there is a definable end member, corresponding to a definable reservoir, the "depleted MORB mantle". It is a hangover from thinking of the mantle as layered. However the geophysical evidence is inconsistent with such a conception, except for the $\mathrm{D}^{\prime \prime}$ region. Instead, the evidence is clear that the bulk of the mantle is heterogeneous in all respects. In that case we would expect the heterogeneity of the source to give

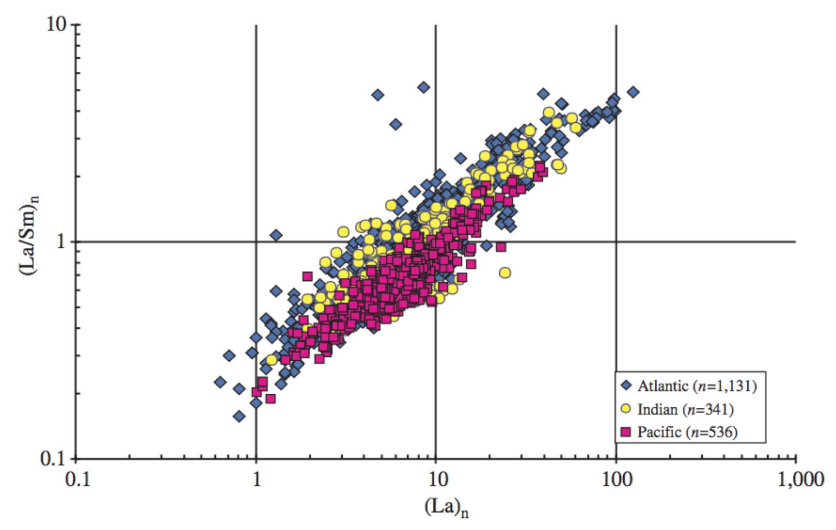

Fig. 20. $\mathrm{La} / \mathrm{Sm}$ versus $\mathrm{La}$, normalised to primitive-mantle, for MORB from three Ocean basins. Lanthanum concentrations vary by about two orders of magnitude; $\mathrm{La} / \mathrm{Sm}$ varies by more than one order of magnitude. Data were extracted from PETDB. From Hofmann (2003). Copyright Elsevier Science. Reprinted with permission.

rise to heterogeneity of MORBs, as illustrate in Fig. 7b, and as is observed.

For considering both mass balances and mantle heat generation it is the mean composition of the mantle that is important. That mean must include all components, whether they have been considered enriched, anomalous, plume-related or whatever. Because the more enriched components have been excluded from most considerations, the resulting estimates may be significantly in error, as we will see.

\subsection{Chemical disequilibrium}

It was emphasised in Sect. 4 that if the mantle is heterogeneous in major elements and lithology then the bulk extraction of incompatible elements will not be governed just by local equilibrium chemical partitioning, but may be strongly affected by the vagaries of the migration of melts that are out of equilibrium with the peridotite matrix. As emphasised, significant quantities of melts may become trapped and remain in the residual zone from which (some) melts are extracted. Equally, such melts may not have equilibrated with their local environment so, for example, the peridotite matrix may not register their nearby presence.

Two recent estimates of the MORB-source composition (Salters and Stracke, 2004; Workman and Hart, 2005) use the composition of peridotites in key parts of their arguments. The trace element concentrations estimated by Salters and Stracke are deduced from major elements through a correlation between lutetium, a compatible trace element, and $\mathrm{CaO}$ in anhydrous spinel peridotites (Fig. 21). However the peridotites may not have equilibrated with the higher Lu content of eclogitic and pyroxenitic heterogeneities. Thus the Lu in the peridotites can only be regarded as a lower bound on the Lu content of the whole source. All of the other trace element 


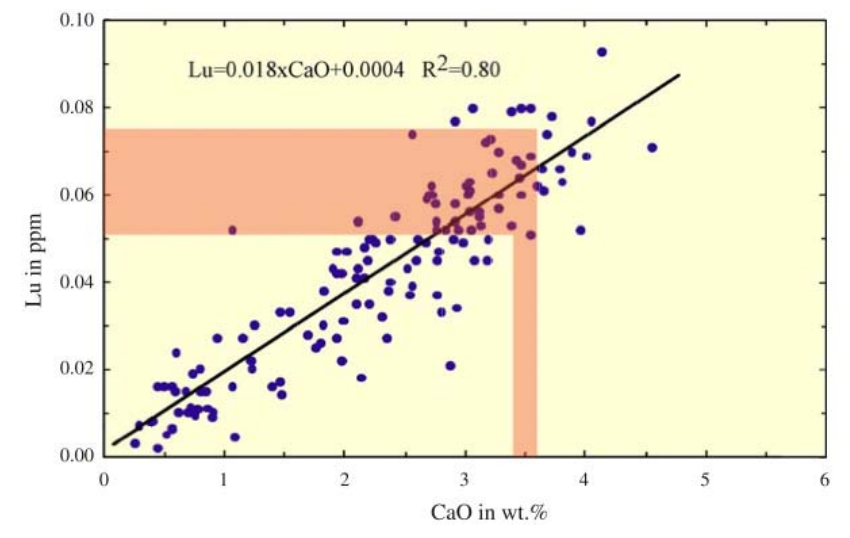

Fig. 21. $\mathrm{Lu}$ variations with $\mathrm{CaO}$ in anhydrous spinel peridotites. Mantle $\mathrm{Lu}$ is inferred assuming $3.50 \mathrm{wt} \% \mathrm{CaO}$ for the depleted mantle. From Salters and Stracke (2004). Copyright American Geophysical Union.

concentrations in the analysis of Salters and Stracke are tied to the Lu content, so the trace element content of the source would only be a lower bound.

The estimate by Workman and Hart starts from the traceelement composition of clinopyroxenes from abyssal peridotites. Those peridotites likewise may not have equilibrated with enriched heterogeneities, so their estimates would also be lower bounds on the trace element content of the whole source.

It is notable that Salters and Dick (2002) found that isotopes in some MORBs from the Indian Ocean could not be explained as products of nearby abyssal peridotites, but implied an additional enriched component. They note that pyroxenites and eclogites are rare at mid-ocean ridges, though common among xenoliths and peridotite massifs, and inferred that enriched heterogeneities had been melted out of the source before it reached the surface. In that case the residual peridotites would fail to represent the incompatible elements in those heterogeneities.

The estimates by Salters and Stracke and by Workman and Hart are also vulnerable in other respects. They both rely on equilibrium melting models for a homogeneous source, and both use long chains of inference. (Workman and Hart use equilibrium relationships to deduce whole rock composition from the clinopyroxenes.) Salters and Stracke's estimate of thorium content depends on a chain of no less than eight elemental ratios. $\mathrm{U}$ and $\mathrm{K}$ require a further ratio each. Workman and Hart begin with a reconstruction of whole-rock composition, which requires partition coefficients and modal abundances, then a melting model to estimate pre-melt composition. Both studies focus on establishing the composition of what they call the depleted mantle, to the exclusion of more enriched components. Thus both should be regarded as having established lower bounds on the trace element content of the MORB source.
Table 2. Average MORB compositions

\begin{tabular}{llll}
\hline & $\begin{array}{l}\mathrm{Nb} \\
\mu g^{-1}\end{array}$ & $\begin{array}{l}\mathrm{Th} \\
\mathrm{ngg}^{-1}\end{array}$ & $\begin{array}{l}\mathrm{U} \\
\mathrm{ngg}^{-1}\end{array}$ \\
\hline "All MOR"a & 5.95 & 400 & 240 \\
N-MORB $^{\mathrm{b}}$ & 2.33 & 120 & 47 \\
EPR Avg $^{\mathrm{c}}$ & 3.79 & 200 & 80 \\
E-MORB $^{\mathrm{b}}$ & 8.3 & 600 & 180 \\
MARK E-MORB & 16.05 & 1100 & 305 \\
\hline
\end{tabular}

${ }^{a}$ Raw averages from PetDB, www.petdb.org/petdbWeb/

$\mathrm{b}$ (Sun and McDonough, 1988)

${ }^{c}$ (Donnelly et al., 2004)

\subsection{Counting all components}

There seem to be no relevant compilations of the mean mantle composition including all components, so some estimates must suffice here to illustrate the magnitude of the change of perspective. An indication of the effect of including most MORB values is shown in Table 2, which lists abundances of $\mathrm{Nb}$, Th and $\mathrm{U}$. The first row shows simple raw averages from the category "All mid-ocean ridges" from the PetDB database. The other rows show comparison values for two estimates of "normal MORB" and two enriched MORBs. U in the all-MORB average is 3-5 times larger than previous MORB estimates.

It may be that $\mathrm{U}$ values are less reliable because $\mathrm{U}$ concentrations are very low, so $\mathrm{Th}$ and $\mathrm{Nb}$ values have been included. Typical MORB ratios are $\mathrm{Th} / \mathrm{U}=2.6$ and $\mathrm{Nb} / \mathrm{U}=47$ (Hofmann, 2003), so these are suitable proxies. All-MOR Th values are 2-3 times larger than previous estimates, while $\mathrm{Nb}$ values are 1.6-2.6 times greater. These factors may be minima, because plume-affected ridge segments may have been excluded from the "all-MOR" category of PetDB, though this is not clear from the PetDB summaries.

The role of mantle plumes also needs to be taken into account. Plumes inject material from the deep mantle, presumably including material from $\mathrm{D}^{\prime \prime}$, into the shallow mantle. We can hope to define the $\mathrm{D}^{\prime \prime}$ zone and make some estimate of its composition of $\mathrm{D}^{\prime \prime}$ (as will be done in Sect. 7), but there is no way to define a zone or zones occupied by plume material that has risen into the mantle interior. If we are to count all of the $U$ that contributes to the Earth's mass balance of $\mathrm{U}$, and that contributes to heating the mantle, then we must include such dispersed plume material in the MORB source tally. It turns out to comprise a surprisingly large fraction of the mantle.

Although the heat flow carried by plumes is secondary to the heat flow associated with plate formation, the mass flow in plumes is relatively large, because the temperature difference between plumes and ambient mantle is smaller than that between subducted plates and ambient mantle. This implies 
Table 3. Enrichments of plume components.

\begin{tabular}{llll}
\hline & $\mathrm{Nb}$ & $\mathrm{Th}$ & $\mathrm{U}$ \\
\hline Hawaii/N-MORB & 2.2 & 2.9 & 2.4 \\
EM1/N-MORB & 13 & 24 & 15 \\
EM2/N-MORB & 11 & 42 & 24 \\
HIMU/N-MORB & 17 & 28 & 18 \\
\hline
\end{tabular}

Values taken from Hofmann (2003) Fig. 20. N-MORB: "normal MORB"; EM1: enriched mantle 1; EM2: enriched mantle 2; HIMU: high ${ }^{238} \mathrm{U} / 204 \mathrm{~Pb}$ (White, 1985; Zindler and Hart, 1986).

that relatively more plume mass has to flow to account for the heat carried by plumes.

The rate of subduction of sea floor is $3 \mathrm{~km}^{2} \mathrm{yr}^{-1}$ (Parsons, 1982). The strongly differentiated part of the lithosphere is about $60 \mathrm{~km}$ deep, so the volume of heterogeneous lithosphere added per year to the MORB source is around $180 \mathrm{~km}^{3} \mathrm{yr}^{-1}$. On the other hand the volumetric flow rate of the Hawaiian plume is estimated to be about $7.5 \mathrm{~km}^{3} \mathrm{yr}^{-1}$ (Davies, 1992) and the Hawaiian plume carries about $10 \%$ of the global plume flow, so the global volumetric flow rate of plumes into the upper mantle is about $75 \mathrm{~km}^{3} \mathrm{yr}^{-1}$. This is about $40 \%$ of the plate flow, or $30 \%$ of the combined flows into the MORB source. Thus the mass flow of plumes is less than that of subducted lithosphere, but only by about a factor of about three.

Most of the plume heterogeneity will not be removed by melting, but will be stirred into the mantle (Davies, 1999b). The volumetric eruption rate of the Hawaiian plume has been about $0.03 \mathrm{~km}^{3} \mathrm{yr}^{-1}$ over the past $25 \mathrm{Myr}$ (Clague and Dalrymple, 1989). Even allowing for substantial subsurface emplacement of magmas, this implies that magmas represent only around $1 \%$ of the volume of the plume. If these magmas were derived by $5 \%$ melting of the plume (Hofmann and White, 1982), then only $20 \%$ of the plume would have melted, and the remainder would be stirred unaltered into the mantle.

An indication of the contribution of plume-related heterogeneities can be obtained from Table 3, which shows the enrichments of various classes of OIBs relative to conventionally-defined normal MORBs for $\mathrm{Nb}$, Th and $\mathrm{U}$. Hawaiian OIB is enriched by a factor of $2-3$, whereas the other OIBs are enriched by factors of 10-40, with a mean of around 20. The higher enrichments are probably due in part to relatively low melt fractions (Hofmann, 2003), so they may be upper bounds on the mean enrichments of the associated plumes.

Table 4 shows the effect of such plume enrichments on the mean composition of the MORB source, assuming plume material comprises $25 \%$ of the mantle interior (the MORB source) as estimated above. If plumes are enriched by factors of 3-5 relative to the "depleted MORB mantle", then the mean mantle concentrations of incompatible elements are in-
Table 4. MORB-source enrichments due to plume components

\begin{tabular}{cc}
\hline $\begin{array}{c}\text { Plume } \\
\text { enrichment }\end{array}$ & $\begin{array}{c}\text { MORB-source } \\
\text { enrichment }\end{array}$ \\
\hline 2 & 1.25 \\
3 & 1.5 \\
5 & 2 \\
10 & 3.25 \\
\hline
\end{tabular}

Enrichment factors are relative to "depleted MORB mantle" inferred from "normal MORB". Plume material is assumed to comprise one quarter of MORB-source material (see text).

creased by factors of 1.5-2. Greater enrichments cannot be ruled out at this stage.

Both the compilation of "all MOR" data in Table 2 and the estimates of plume contributions in Table 4 give ample reason to suspect that the inventories of incompatible trace elements are up to twice conventional estimates, perhaps even more. These considerations are potentially sufficient to account for the "missing" trace elements, even if the mantle is chondritic. If the mantle is more depleted than chondritic then the mass balances are easily accommodated in the geophysically-motivated mantle depicted in Fig. 1.

There is a large data base of MORB compositions, and a more thorough analysis of it that includes all types of samples in proportion to their likely occurrence, without arbitrary exclusions, might yield a more reliable estimate. However any such average may still be sensitive to the smaller number of relatively enriched samples, so uncertainties will need to be carefully considered.

\subsection{The melt extraction zone and the degree of melting}

The degree of partial melting in the MOR melting zone has played no part in the arguments presented so far. This is in contrast to many previous considerations, in which the degree of melting is a fundamental parameter used to calculate melt composition during equilibrium melting. Because the processes considered here involve heterogeneity and disequilibrium, the degree of melting is not easily inferred nor applied. However because the average degree of melting is often invoked, it is instructive to examine how it relates to the present picture.

A simpler way of estimating the MORB source composition than those discussed in Sect. 6.2 is, conceptually, to distribute the trace element content of MORB into the melting zone, or, equivalently, to multiply MORB concentrations by the average degree of partial melting in the melt zone. This requires estimates of the size of the melting zone or of the degree of partial melting. The approaches of Salters and Stracke and Workman and Hart evidently were intended to avoid the need for such estimates, although each invokes equilibrium melting models at some stage in the chain of 
reasoning. Moreover the simpler approach is still often invoked, at least as a rough estimate.

There are two problems with this simpler approach. First, even if the source is homogeneous there are assumptions involved that may not be commonly recognised. Second, heterogeneous melting may cause the melt extraction zone to be significantly smaller than the zone within which some melting occurs, as is clear from the earlier discussion in Sect. 4 (Fig. 15). The implicit melting models, and associated formulas, are given in Appendix A.

The result of these considerations is that this simple approach can also be misleading. In particular, with heterogeneous melting the melt extraction zone is likely to be smaller than the melting zone, and if this is not recognised then concentrations inferred from MORB will be underestimated. Thus this approach is also likely to have over-estimated the degree of depletion of the MORB source.

\section{Mass balances and the heat budget}

An apparent difficulty with the geophysically-based mantle structure illustrated in Fig. 1 has been that it has not seemed to accommodate the Earth's chondritic complement of refractory incompatible trace elements nor of ${ }^{40} \mathrm{Ar}$ (Wasserburg and DePaolo, 1979; Allegre et al., 1987, 1996; Kellogg et al., 1999). With the conventional interpretation that the MORB source is both strongly depleted and strongly degassed, the amounts of these elements that are observed or inferred to be in the continental crust, the oceanic crust and the MORB source account for only about half of the amounts inferred from chondritic meteorites. Therefore an extra "enriched" or "primitive" reservoir has been invoked, presumed to be present in the deep mantle and evidently difficult to detect seismically.

The earlier versions, in which the deep layer was identified with the entire lower mantle, are inconsistent with the evidence from seismic tomography that subducted lithosphere penetrates deep into the lower mantle (Grand et al., 1997), and most investigators have abandoned them. Another version is that a deep layer comprises about the lowest $1000 \mathrm{~km}$ of the lower mantle and contains about half of the budget of relevant elements (Kellogg et al., 1999). More recently Carlson and Boyet (Boyet and Carlson, 2005, 2006; Carlson and Boyet, 2008) have noted that if the bulk Earth is chondritic, their inference from ${ }^{142} \mathrm{Nd}$ that the observable crust and mantle are more depleted than chondritic would require a hidden reservoir that is more enriched than chondritic, containing perhaps $30 \%$ of the Earth's complement of incompatibles. However if the bulk Earth is itself depleted then the need for a hidden reservoir is reduced or perhaps eliminated.

The difficulty with proposals for a deep reservoir is not simply that such geophysical evidence as has been offered for a deep mantle layer is not compelling (van der Hilst and Kárason, 1999). The larger difficulty is that the Earth's to- pography precludes much of the Earth's heat flow from coming from deeper than the source of mantle plumes, otherwise plumes and the topography they produce would be much stronger than they are observed to be. This means that either there is more heat generated above the depth in the mantle from which plumes come or there is less heat generated in the Earth than either geochemistry or geophysics have suggested.

In Sects. 4 and 6 several reasons were presented why previous estimates of MORB source composition have overestimated the degree of depletion, and thus under-estimated the incompatible element content. Here the mass balances and heating implications of the various possibilities will be examined. It is convenient to use uranium as a representative of the refractory incompatible trace elements, in a mass balance, and as a representative of the main heat-generating elements, in a heat budget.

\subsection{Uranium mass balance}

Table 5a summarises estimates of uranium concentration in the Earth, assuming it is chondritic, and in its main reservoirs (Davies, 2009b). The average $U$ content of the primitive mantle is inferred from chondritic meteorites to be $20 \pm 4 \mathrm{ng} \mathrm{g}^{-1}$, which implies a total mass of $80 \times 10^{15} \mathrm{~kg}$ of U. (Concentrations are given as nanograms of uranium per gram of rock, rather than as "parts per billion". This removes the ambiguity of whether the ratio is by weight, volume or mole.) About $(23-47) \times 10^{15} \mathrm{~kg}$ is estimated to be in the continental crust, i.e. $30-60 \%$. Thus $(33-57) \times 10^{15} \mathrm{~kg}$ or $40-70 \%$ is inferred to be in the mantle.

Some of this mantle uranium we can plausibly locate in the seismic $\mathrm{D}^{\prime \prime}$ zone at the bottom of the mantle. $\mathrm{D}^{\prime \prime}$ is interpreted here as including accumulations of subducted oceanic crust, and the accumulation is taken, from numerical models like that of Fig. 4, to be equivalent to a layer of pure oceanic crust about $100 \mathrm{~km}$ thick. If its $\mathrm{U}$ content is similar to that of oceanic crust then it would contain only about $5 \%$ of the total U budget. This leaves about half of the Earth's chondritic complement of $\mathrm{U}$ unaccounted for.

According to the mantle picture summarised in Sect. 2, the only remaining mantle reservoir is the rest of the mantle, in other words excluding the crust and the $\mathrm{D}^{\prime \prime}$ layer. By implication this is also the MORB source region. The balance of the Earth's uranium would then be required to be in this reservoir, and Table 5 shows it would have a concentration of about $10 \pm 3 \mathrm{ng} \mathrm{g}^{-1}$. This is significantly higher than traditional estimates of 3-4.7 $\mathrm{ng} \mathrm{g}^{-1}$ (Jochum et al., 1983; Salters and Stracke, 2004; Workman and Hart, 2005). It was argued in Sect. 6 that those estimates are lower bounds. Although the preliminary versions of more complete estimates given in Sect. 6 are not very accurate at this stage, they seem to leave open the possibility that the balance of the chondritic abundances could be accommodated in the MORB source. 
Table 5. Uranium and heat generation budgets ${ }^{\mathrm{a}}$.

\begin{tabular}{|c|c|c|c|c|c|c|}
\hline Reservoir & $\begin{array}{l}\text { Mass } \\
10^{22} \mathrm{~kg}\end{array}$ & $\begin{array}{l}\text { Mass } \\
\%\end{array}$ & $\begin{array}{l}\text { U conc. } \\
\mathrm{ng} \mathrm{g}^{-1}\end{array}$ & $\begin{array}{l}\text { U mass } \\
10^{15} \mathrm{~kg}\end{array}$ & $\begin{array}{l}\text { Heat } \\
\text { gen. }^{\text {b }} \\
\text { pW kg }^{-1}\end{array}$ & $\begin{array}{l}\text { Heat } \\
\text { gen. } \\
\text { TW }\end{array}$ \\
\hline \multicolumn{7}{|l|}{ (a) Chondritic } \\
\hline \multicolumn{7}{|l|}{ Average silicate } \\
\hline Earth & 400 & 100 & $20^{\mathrm{c}}$ & 80 & 5 & 20 \\
\hline Continental crust & 2.6 & 0.65 & $\begin{array}{l}1400^{\mathrm{d}} \\
(900-1800)\end{array}$ & $\begin{array}{l}36 \\
(23-47)\end{array}$ & $\begin{array}{l}350 \\
(225-450)\end{array}$ & $\begin{array}{l}9 \\
(6-12)\end{array}$ \\
\hline $\mathrm{D}^{\prime \prime}$ & 8.5 & 2.1 & $\begin{array}{l}50^{\mathrm{e}} \\
(50-80)\end{array}$ & $\begin{array}{l}4 \\
(4-7)\end{array}$ & $\begin{array}{l}10.5 \\
(10-15)\end{array}$ & 1 \\
\hline $\begin{array}{l}\text { MORB source, } \\
\text { i.e. rest of mantle }\end{array}$ & 389 & $\begin{array}{l}97 \\
(6.5-13)\end{array}$ & $\begin{array}{l}\mathbf{1 0} \\
(26-53)\end{array}$ & $\begin{array}{l}40 \\
(1.5-3)\end{array}$ & $\begin{array}{l}2.5 \\
(7-13)\end{array}$ & 10 \\
\hline \multicolumn{7}{|c|}{ (b) Non-chondritic ( $70 \%$ depleted) } \\
\hline Silicate Earth & 400 & 100 & 14 & 56 & 3.5 & 14 \\
\hline Continental crust & 2.6 & 0.65 & $1400^{\mathrm{d}}$ & 36 & 350 & 9 \\
\hline $\mathrm{D}^{\prime \prime}$ & 8.5 & 2.1 & $50^{\mathrm{e}}$ & 4 & 10.5 & 1 \\
\hline MORB source & 389 & 97 & 4 & 16 & 1.0 & 4 \\
\hline
\end{tabular}

a (Plausible ranges in parentheses.)

Bold numbers inferred from $\mathrm{U}$ mass balance. $1 \mathrm{pW}=1$ picowatt $=10^{-12} \mathrm{~W} .1 \mathrm{TW}=1$ terawatt $=10^{12} \mathrm{~W}$

${ }^{\mathrm{b}}$ Heat generation productivity from Stacey (1992), assuming $\mathrm{Th} / \mathrm{U}=3.8$ and $\mathrm{K} / \mathrm{U}=13000$.

c (McDonough and Sun, 1995; O’Neill and Palme, 1998; Lyubetskaya and Korenaga, 2007).

d (Rudnick and Fountain, 1995)

e Assumed similar to oceanic crust; (Sun and McDonough, 1988; Donnelly et al., 2004)

The bulk of the mantle would therefore be depleted only by about a factor of two relative to the chondritic standard.

On the other hand the ${ }^{142} \mathrm{Nd}$ observations imply that the observable silicate Earth is depleted by about $30 \%$ relative to chondrites (Carlson and Boyet, 2008). Table 5b gives the mass balance assuming the bulk $\mathrm{U}$ content is $70 \%$ of chondritic. This requires the MORB source concentration to be only $4 \mathrm{ng} \mathrm{g}^{-1}$, which is within the range of the recent geochemical estimates quoted above. The MORB source would be depleted by a factor of 3.5 relative to the bulk Earth in this case. Thus the proposed non-chondritic Earth seems to reconcile the geophysically-inferred mantle structure of Fig. 1 with the mass balances of the refractory incompatible elements.

\subsection{Topographic constraint on mantle layers}

At any horizontal boundary within the Earth that prevents vertical flow of material, including the core-mantle boundary, vertical heat transport must be by conduction (i.e. advection is not possible). As heat conducts into the layer above the boundary it will form a thermal boundary that will be buoyant. If the rate of heat flow is sufficient (it usually will be) the thermal boundary layer will become unstable and rise buoyantly. As such a buoyant upwelling approaches the top of the mantle its buoyancy will lift the Earth's surface, generating topography. It turns out there is a simple and direct relationship between the rate of heat flow up the upwelling and the magnitude of the topography generated at the surface (Davies, 1988b; Sleep, 1990; Davies, 1999b, 2011). A comparable relationship applies to topography generated by a cooling thermal boundary layer at the surface, i.e. to the seafloor subsidence caused by the cooling oceanic lithosphere (Davies, 1988b, 1999b).

The manifestation of this process is sketched in Fig. 22 for two proposed mantle structures. The deep layer proposed by Kellogg et al. (1999) (Fig. 22a) would contain about half of the Earth's radioactive heat generation, whereas the Carlson and Boyet (2008) hidden layer would contain about $30 \%$. These would generate strong upwellings in the upper layer that would in turn generate substantial topography, about $30-50 \%$ of the magnitude of the mid-ocean ridge topography. On the other hand if only a little heat enters the mantle, from the core and the $\mathrm{D}^{\prime \prime}$ layer, then weaker upwellings and smaller topography would result (Fig. 22b).

The only topography that can be identified with buoyant mantle upwellings is the hotspot swells. The magnitude of these swells, singly or collectively, is in no way comparable to the magnitude of the mid-ocean ridge topography, so the proposed deep layers are inconsistent with the topography of the Earth's surface.

The buoyancy implied by the various hotspot swells translates to a collective heat flow of about 3.5 TW (Davies, 1988b; Sleep, 1990). The cooling oceanic lithosphere and 

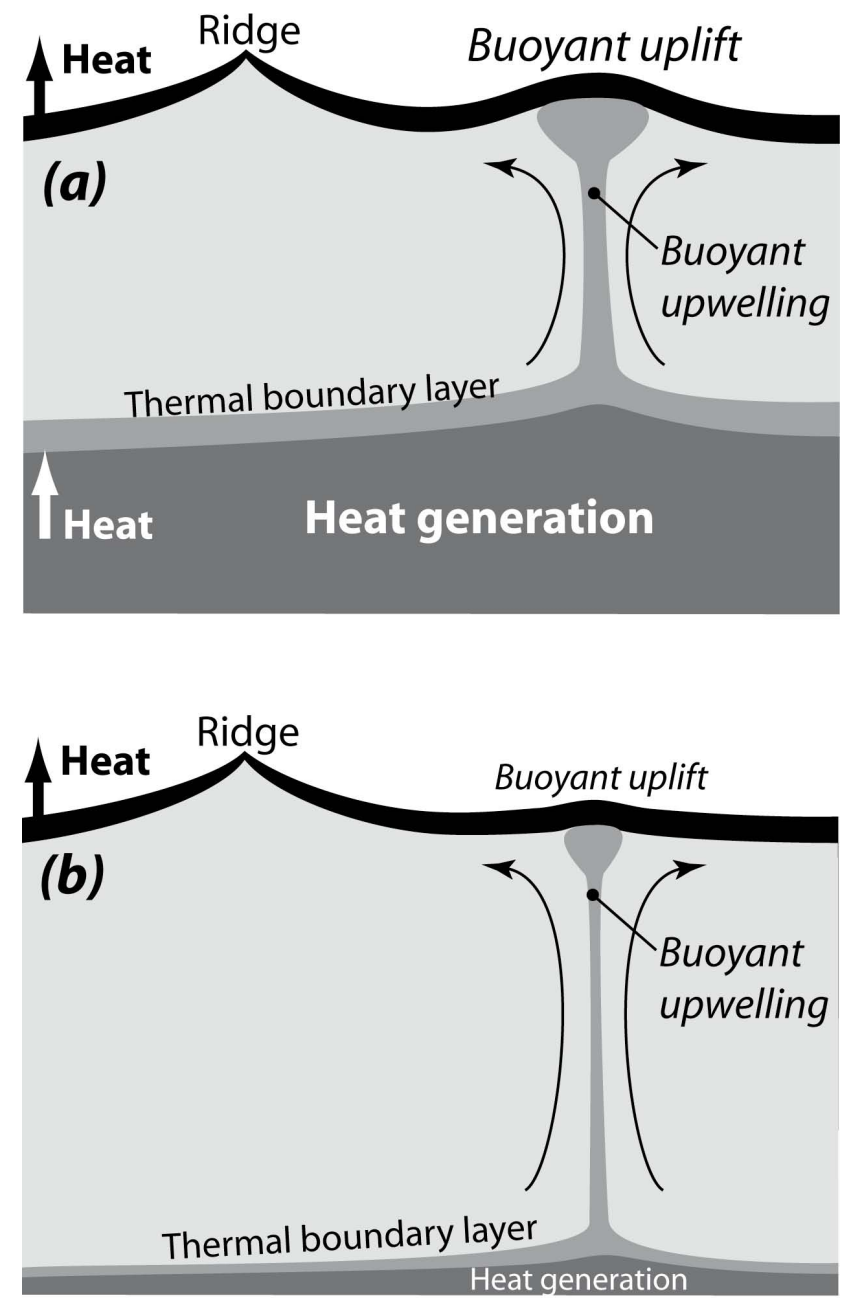

Fig. 22. Sketches of relationship between heating and topography. (a) A thick lower layer supplies strong heating to the base of the upper layer, generating a strong buoyant upwelling and large topography. (b) A thin layer supplies only a small amount of heat, generating a weaker upwelling and small topography.

the mid-ocean ridge topography it generates involves a heat flow of about $30 \mathrm{TW}$ (Davies, 1988b, 1999b). Thus the plume topography implies only about $10 \%$ of the heat flow of the mid-ocean ridges. These relationships will be made more explicit in the following Section.

When the relationship between hotspot swells and plume heat flow was first pointed out it was presumed to reflect the amount of heat flowing into the base of the mantle (the inferred source of mantle plumes) from the core. More recently modelling of mantle plumes has revealed that the temperature difference between a plume and its surroundings decreases by around $50 \%$ as the plume rises through the mantle (Labrosse, 2002; Bunge, 2005; Leng and Zhong, 2008). This implies that the heat flow also decreases as the plume rises, or in other words that the heat transported by plumes near the bottom of the mantle is about twice the amount transported near the top. Thus plumes are inferred to carry around 7 TW of heat from the bottom of the mantle (Davies, 2007). This is important for considering the mantle heat budget, as follows.

\subsection{Heat budget}

The radioactive heat production implied by the above uranium budgets is included in Table 5. The main heatproducing elements are uranium, thorium and potassium, and standard ratios of $\mathrm{Th}$ and $\mathrm{K}$ to $\mathrm{U}$ are used (Table 5). The $9 \mathrm{TW}$ of heat generated in the continental crust is conducted directly to the surface, and is therefore not involved in driving the mantle. In the chondritic case (Table 5a), about $90 \%$ $(10 \mathrm{TW})$ of the heat generated within the mantle is generated in the MORB source, the balance (1 TW) coming from $\mathrm{D}^{\prime \prime}$. In the non-chondritic case about $80 \%$ is generated in the MORB source.

The mantle heat budget involves not only the heat generated by radioactivity but also heat flowing in from the core and heat released by the slow cooling of the mantle. Models of the thermal evolution of the core, taking account of the growth of the inner core and the energy required to generate the Earth's magnetic field, indicate a heat flow out of the core of about 5-7 TW (Davies, 2007), reasonably consistent with estimates based on seismological and other constraints (Lay et al., 2008), as is discussed in more detail by Davies (2009b). Conventional parameterised thermal evolution models of the mantle, and numerical convection models, indicate a rate of cooling of around $70^{\circ} \mathrm{C} / \mathrm{Gyr}$, which releases 9 TW of heat (Davies, 1993).

A heat budget for the kind of mantle illustrated in Fig. 1 is shown in Fig. 23a, based on the total chondritic radiogenic heat production of $20 \mathrm{TW}$ from Table $5 \mathrm{a} .6 \mathrm{TW}$ is presumed to come from the core, and $1 \mathrm{TW}$ of radiogenic heat is added to this in $\mathrm{D}^{\prime \prime}$. Plumes rise from the top of $\mathrm{D}^{\prime \prime}$, and therefore carry $7 \mathrm{TW}$ of heat. This reduces to $3.5 \mathrm{TW}$ as the plume arrives in the upper mantle, thus matching the heat flow inferred from hotspot swells (Davies, 1988b; Sleep, 1990). Only a very small fraction of this heat leaks out through the lithosphere, and the rest is delivered to the mantle interior. The other half of the initial plume heat is lost to the mantle interior on the way up. Thus the $7 \mathrm{TW}$ from the core and $\mathrm{D}^{\prime \prime}$ are delivered into the mantle. To this are added $10 \mathrm{TW}$ of radiogenic heat in the mantle (Table 5a) and 9 TW from cooling of the mantle, making a total of $26 \mathrm{TW}$. This amount of heat is removed from the mantle by the action of plate tectonics (the top boundary layer removes heat from the interior). In this model the MORB source is heated only $27 \%$ from below.

The effect of the deep, thick layer proposed by Kellogg et al. (1999) is illustrated in Fig. 23b. This layer was hypothesised to contain most of the incompatible elements that are not in the continental crust, so it would generate about $10 \mathrm{TW}$ of radiogenic heat. It comprises about a third of the mantle mass, so it would contribute about $3 \mathrm{TW}$ from cooling. Thus 


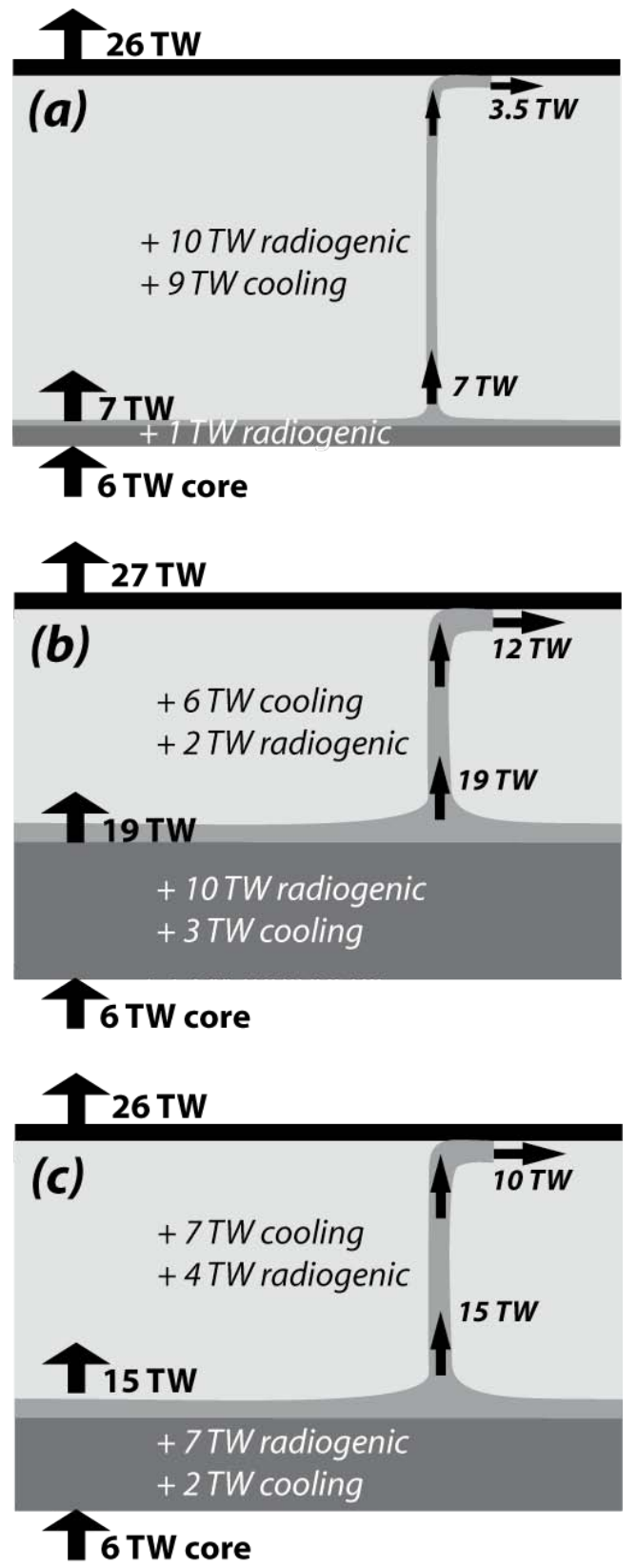

Fig. 23. Heat budgets of alternative mantle models. (a) Preferred model: thin $\mathrm{D}^{\prime \prime}$ region and a mildly depleted MORB source comprising most of the mantle. (b) Deep mantle layer containing about half of the Earth's refractory incompatible elements. (c) Deep hidden layer that would ensure chondritic overall composition, as proposed by Carlson and Boyet (2008). Only (a) is consistent with observed hotspot swells. See text for details.

a total of $19 \mathrm{TW}$ would emerge through the top interface of this layer. This is where plumes would originate, so they would carry $19 \mathrm{TW}$ initially. They would lose perhaps one third of their heat rising through the rest of the mantle, so delivering about $12 \mathrm{TW}$ to the upper mantle. This would generate topography 3-4 times larger than the observed hotspot topography. The upper two-thirds of the mantle would yield $6 \mathrm{TW}$ from cooling and perhaps $2 \mathrm{TW}$ of radiogenic heat, reflecting the strong depletion assumed for the MORB source. The plates would then remove the total of $27 \mathrm{TW}$ from the mantle. In this model the MORB source is heated $70 \%$ from below.

Finally the possible hidden layer noted by Carlson and Boyet (2008) is depicted in Fig. 23c. About 6 TW from this layer and $1 \mathrm{TW}$ from $\mathrm{D}^{\prime \prime}$ above it, plus about $2 \mathrm{TW}$ from cooling would yield $15 \mathrm{TW}$ emerging into the plume-generating layer. Of this around $10 \mathrm{TW}$ would reach the upper mantle in plumes. Again this is around 3 times the heat flow implied by observed hotspot swells.

Thus the observed topography of the sea floor precludes a deep layer containing a substantial fraction of the Earth's heat sources, quite apart from seismological observations, which provide no clear evidence for mantle layering apart from $\mathrm{D}^{\prime \prime}$.

\subsection{The argon mass balance}

The ${ }^{40} \mathrm{Ar}$ budget has been a problem for the chondritic Earth model. As with uranium, this problem is considerably relieved if the Earth is more depleted than chondritic. There are also significant uncertainties in other components of the argon budget that bear discussion. These are of less import for the non-chondritic Earth model, but ought still to be appreciated. As well, it is possible they would resolve the problem even for the chondritic model.

The noble gas evolution model reproduced in Sect. 5 yielded a final ${ }^{40} \mathrm{Ar}$ abundance in the MORB source of $12 \times 10^{13}$ atoms/g (Davies, 2010), which is only $55 \%$ of that required $\left(22 \times 10^{13}\right.$ atoms $\left./ \mathrm{g}\right)$ to balance the usual estimate of the Earth's ${ }^{40} \mathrm{Ar}$ budget $\left(50 \times 10^{13}\right.$ atoms $\left./ \mathrm{g}\right)$. D" can hold only perhaps $3 \%$. With about $50 \%$ in the atmosphere and $27 \%$ in the MORB source, this seems to leave about $20 \%$ still unaccounted for. This model has higher concentrations in the MORB source than has been usually assumed, consistent with the discussion of Sect. 6, and the final deficit is much smaller than has been conventionally inferred (Allegre et al., 1996), and we should consider whether it is significant given the uncertainties involved. On the other hand the nonchondritic Earth model would imply around $30 \%$ less $\mathrm{K}$ and less $\mathrm{Ar}$, so there might be no remaining discrepancy.

The K/U ratios in both the mantle and the crust are debated, and have significant uncertainty. The mantle ratio might be lower (Albarède, 1998; Lassiter, 2004) or higher (Arevalo et al., 2009) than the value of 13000 (Jochum et al., 1983) commonly used. There may also be less $\mathrm{K}$ in the continental crust than is often estimated. For example Taylor and McLennan (1985) estimated the $\mathrm{K}_{2} \mathrm{O}$ content of the continents to be $1.1 \%$, compared with Rudnick and Fountain's (1995) $1.9 \%$. The continental crust is so heterogeneous it is doubtful any estimates can have great accuracy. 
Table 6. Potassium budget.

\begin{tabular}{|c|c|c|c|c|}
\hline Reservoir & $\begin{array}{l}\text { Mass } \\
10^{22} \mathrm{~kg}\end{array}$ & $\begin{array}{l}\text { Mass } \\
\%\end{array}$ & $\begin{array}{l}\mathrm{K} \text { conc. } \\
\mu \mathrm{g} \mathrm{g}^{-1}\end{array}$ & $\begin{array}{l}\mathrm{K} \text { mass } \\
10^{20} \mathrm{~kg}\end{array}$ \\
\hline \multicolumn{5}{|l|}{ Continental crust } \\
\hline Taylor \& McLennan ${ }^{\mathrm{a}}$ & 2.6 & 0.65 & $(1.1 \%)$ & 2.4 \\
\hline Rudnick and Fountain ${ }^{b}$ & & & $(1.9 \%)$ & 4.15 \\
\hline $\mathrm{D}^{\prime \prime}$ & 8.5 & 2.1 & 650 & 0.55 \\
\hline \multicolumn{5}{|l|}{ MORB source ${ }^{\mathrm{c}}$, } \\
\hline Chondritic Earth & 389 & 97 & 130 & 5.2 \\
\hline Non-chondritic & & & 50 & 2.1 \\
\hline \multicolumn{5}{|l|}{ Bulk Silicate Earth } \\
\hline T\&M, Chondr. & 400 & 100 & 203 & 8.1 \\
\hline R\&F, Chondr. & & & 250 & 9.9 \\
\hline T\&M, Non-chondr. & & & 125 & 5.0 \\
\hline R\&F, Non-chondr. & & & 168 & 6.7 \\
\hline
\end{tabular}

a (Taylor and McLennan, 1985).

b (Rudnick and Fountain, 1995).

c Scaled from U abundance, Table 5.

Also, we should not really assume the Earth has retained all of its volatiles, because some of the atmosphere may have been blasted off by very large impacts during the late stages of accretion, or by the late heavy bombardment if that was a separate episode (Melosh and Vickery, 1989). Bombardment persisted until about $3.8 \mathrm{Ga}$, by which time about one third of the Earth's ${ }^{40} \mathrm{Ar}$ had been generated. If mantle degassing was rapid during the first $0.5 \mathrm{Gyr}$ or so, then it is conceivable that the order of $10 \%$ of the Earth's ${ }^{40} \mathrm{Ar}$ was removed from the Earth entirely (Davies, 1999a).

Estimates of the $\mathrm{K}$ abundance in the main reservoirs are summarised in Table 6, including alternatives for the continental crust and the MORB source. Thus, for example, we can sum the mass of $\mathrm{K}$ in the crust using Taylor and McLennan's estimate, $\mathrm{D}^{\prime \prime}$ and MORB source to get a total of $8.1 \times 10^{20} \mathrm{~kg}$ of $\mathrm{K}$ and a bulk silicate Earth concentration of $203 \mathrm{~g} \mathrm{~g}^{-1}$. This compares with the more usual estimate, based on the chondritic assumption, of around $240 \mathrm{~g} \mathrm{~g}^{-1}$ (McDonough and Sun, 1995), but the total K content of the Earth has significant uncertainty because of the volatility of $\mathrm{K}$ during the planetary accretion process (McDonough, 2003). This reduced $\mathrm{K}$ content $\left(203 \mathrm{~g} \mathrm{~g}^{-1}\right)$ would yield $169 \times 10^{40}$ atoms of ${ }^{40} \mathrm{Ar}$ over $4.5 \mathrm{Gyr}$. The inventory for the medium gas evolution model (Sect. 5, (Davies, 2010)) is $48 \times 10^{40}$ atoms in the MORB source and $0.7 \times 10^{40}$ atoms in $\mathrm{D}^{\prime \prime}$. The amount in the continental crust is not well determined but estimated to be about $7 \times 10^{40}$, and the amount in the atmosphere is $99 \times 10^{40}$ (Allegre et al., 1996). These sum to $155 \times 10^{40}$ atoms. An evolution based on the highgas case of Table 1 yields a final total of $170 \times 10^{40}$ atoms, so between them the models span the bulk silicate amount just estimated. Thus a lower crustal abundance of $\mathrm{K}$, and a consequent lower global abundance of $\mathrm{K}$ and $\mathrm{Ar}$, is consistent with the present models.
Alternatively we can assume a non-chondritic Earth and get a bulk silicate Earth concentration of 125-168 $\mathrm{g} \mathrm{g}^{-1}$, depending on the crustal model used. This would yield even less ${ }^{40} \mathrm{Ar}$ and its global budget would be satisfied within the uncertainties, as Boyet and Carlson (2005) already pointed out.

Thus the ${ }^{40} \mathrm{Ar}$ constraint is not as stringent as has been claimed, even for the chondritic Earth model. There are uncertainties in the amount of potassium in the continental crust and in the bulk silicate Earth, and there may have been some early loss of ${ }^{40} \mathrm{Ar}$ from the atmosphere. The model presented in Sect. 5 may account for the total ${ }^{40} \mathrm{Ar}$ budget of a chondritic Earth when these uncertainties are allowed for. The non-chondritic Earth model reveals a previously unrecognised uncertainty also in the cosmochemical abundances incorporated into the Earth, one that resolves the ${ }^{40} \mathrm{Ar}$ question on its own

\subsection{Cosmochemical abundances and thermal evolution}

A long-standing problem with the chondritic Earth model is that the abundances of heat sources $(\mathrm{U}, \mathrm{Th}, \mathrm{K})$ inferred from cosmochemistry seem to be insufficient to allow conventional models of the thermal evolution of the mantle to match the present heat loss from the Earth's interior (Davies, 1993; Korenaga, 2008). With the advent of the more depleted, non-chondritic model inferred from ${ }^{142} \mathrm{Nd}$ (Boyet and Carlson, 2005), this problem becomes more severe.

There are three possible resolutions of this discrepancy. First, the dynamics of the mantle may be incompletely incorporated into conventional evolution models. Second, the present heat loss from the Earth may be unusually high. Third, the cosmochemical estimates of Earth's heat sources may be too low. The three options will be discussed only briefly here.

One version of the first possibility has been advocated by Korenaga (2006, 2008), who argues that lithospheric plate motions are slowed by their strong resistance to bending at subduction zones, and that plate thickness was defined in the past by the dehydration accompanying melting. This would keep plate velocities and heat loss low throughout Earth history. In this scenario the mantle temperature would have peaked at very high values $\left(1600-1700^{\circ} \mathrm{C}\right)$ in the Archean and declined more and more rapidly since, with a current cooling rate of about $150{ }^{\circ} \mathrm{CGyr}^{-1}$ rather than the $70^{\circ} \mathrm{C} \mathrm{Gyr}^{-1}$ assumed in Sect. 7.3. However Korenaga's model depends on assuming a small and unchanging radius of curvature of bending plates, and this is not supported by current observations (Wu et al., 2008) nor by recent modelling that indicates the radius of curvature will be larger for thicker plates (Capitanio et al., 2009). If even modestly more plausible radii of curvature are assumed the recent thermal history reverts to being close to previous conventional histories (Davies, 2009a) and the reconciliation with cosmochemical estimates is lost. It is possible that some other 
overlooked aspect of mantle dynamics will modify our understanding of the thermal evolution of the mantle, but no such mechanism is seems to be proposed at this time.

The second possible resolution is that the present rate of heat loss is unusually high. This would imply the mantle is cooling more rapidly than usual. This might have been true for a few hundred million years without affecting the mantle temperature too dramatically. Some fluctuations in the cooling rate are expected to have occurred just due to normal fluctuations in the age-area distribution of oceanic plates (Labrosse and Jaupart, 2007), but these may not have a large enough amplitude (Cogné and Humler, 2008), or might imply higher rather than lower heat flow in the recent past (Korenaga, 2007).

A more interesting possibility is that plate tectonics might have been intermittent, as suggested by Silver and Behn (2008). This would also imply that our understanding of plate motions is incomplete, though no explicit mechanism for intermittency is offered by Silver and Behn. Intermittency would cause larger fluctuations in heat loss, and would allow the mantle to maintain its temperature over the longer term despite the present imbalance. The apparent episodicity of continental tectonics would be consistent with this, but evidence at this stage is sketchy.

The third possibility is that the cosmochemical estimates are too low. Unfortunately the non-chondritic abundances inferred from ${ }^{142} \mathrm{Nd}$ are even lower than chondritic. Whereas the heating required is at least $50 \%$ more than the chondritic estimate, it is double the non-chondritic estimate, or more. The cosmochemical estimates do depend on a series of assumptions, and their uncertainty is taken by some to be about 30\% (McDonough and Sun, 1995). The discrepancy of heat sources is larger than this. The inference from ${ }^{142} \mathrm{Nd}$ may actually be more robust, as it seems to involve fewer assumptions than the standard chondritic estimates. It also implies that the inner solar system may be less uniform or systematic than the chondritic assumption requires, and thus offers a constraint on the level of randomness that might be involved, a factor that was hitherto very difficult to evaluate. It is thus difficult to argue at this point that the cosmochemical estimates are too low.

\section{Conclusions}

The goals of geochemical and geophysical studies of the mantle must be to arrive at mutually compatible conclusions. The advent of the non-chondritic Earth model inferred from ${ }^{142} \mathrm{Nd}$ reduces the apparent discrepancies concerning mass balances. The numerical and theoretical work on mantle differentiation, stirring and segregation, along with a more thorough consideration of the implications of lithological heterogeneity in the mantle, clarify the relationships among geophysical processes and geochemical observations, and allow any remaining mass balance questions to be resolved. The result is that all of the major discrepancies seem to be within reach of resolution, except that conventional thermal evolution calculations require more internal heating than is predicted from chemical arguments.

Key factors in the resolutions discussed here are the rate of processing of mantle material through the mid-ocean ridge melting zones, the heterogeneity of the mantle at all scales and in all elements, the tendency of some subducted oceanic crust and hybrid pyroxenite to settle to the base of the mantle, and the effect of mantle heterogeneity on melting, melt migration, eruption and the distribution of incompatible elements.

The effect of source heterogeneity on melting and melt migration is quite fundamental. Old geochemical assumptions and habits of thought based on equilibrium melting of a homogeneous source may not apply. Disequilibrium seems likely down to quite small scales, and melt migration will be erratic and governed by strongly interacting physical and chemical processes.

Previous estimates of the incompatible trace element content of the mantle are likely to be lower bounds. Preliminary estimates that avoid inappropriate assumptions are not very accurate at this stage, but they plausibly allow trace element contents to be as much as double previous estimates. Sufficient data exist that better estimates might be made fairly readily.

If the Earth is non-chondritic, then estimated mass balances of incompatible elements in the geophysicallymotivated model sketched in Fig. 1 are plausibly resolved within uncertainties, especially as uncertainties arising from mantle heterogeneity are more fully accounted for. It is even plausible that mass balances can be satisfied in a chondritic Earth.

The numerical modelling of Christensen and Hofmann (1994), and later extensions and refinements described in Sect. 3, have established quantitatively that refractory incompatible trace elements and their isotopes can be accommodated in the dynamic mantle. The apparent-age timescale from lead isotopes is, in this interpretation, an average residence time between passages through the MOR melting zones. The differences among and between MORBs and OIBs is accounted for by the Hofmann and White (1982) hypothesis that some old subducted oceanic crust settles to the $\mathrm{D}^{\prime \prime}$ region, later to be brought up in mantle plumes and contribute to OIBs.

Relatively simple theoretical models of mantle sampling show that little primitive mantle should survive, they give estimates of the amount of oceanic crust in the mantle, and they explain the age distributions of mantle material yielded by numerical models. These results support and elucidate the results from numerical models of stirring by mantle convection.

The noble gases would plausibly come to reside in hybrid pyroxenite, formed when melt from eclogite and pyroxenite pods reacts with surrounding peridotite. A significant 
proportion of such melt may fail to erupt, and would recirculate in the mantle without degassing. Because it is denser than average mantle, some of the hybrid pyroxenite would settle into the $\mathrm{D}^{\prime \prime}$ region, where it can be tapped by mantle plumes. The amount of noble gases in MORBs and relatively unradiogenic noble gases in some OIBs can be quantitatively explained by this model.

It thus seems possible to reconcile the main geochemical observations of the mantle with geophysical and dynamical constraints. One main exception remains, namely the discrepancy between cosmochemical heat source abundances and the present rate of heat loss of the Earth.

\section{Appendix A}

A common expression used by geochemists (e.g. (Hofmann, 2003) p. 81, who uses the equivalent concentration relationship, see below) to relate the thickness of oceanic crust, $d_{\mathrm{c}}$, to the average melt fraction, $f$, in the melt zone is simply

$d_{\mathrm{c}}=f d_{\mathrm{m}}$

where $d_{\mathrm{m}}$ is the depth of first melting. The physical picture implicit in this formula is depicted in Fig. A1a. It is that a column of mantle material is injected vertically into the melt zone. It then partially melts, the melt segregates to the top to form the oceanic crust, and the column moves horizontally with the moving tectonic plate, thus making room for a new column to be injected. This can be called the column injection model. It is essentially a one-dimensional model of vertical injection and vertical melt segregation. It is conceptually simple but of course not physically plausible, because the sharp $90^{\circ}$ turns in mantle flow would involve infinite energy dissipation.

A physically more plausible model, similar to that in Fig. 15a, is depicted in Fig. A1b. This model takes account of the fact that mantle flow will turn from vertical to horizontal over a finite distance, and is intrinsically two-dimensional under MORs. It also takes account of the melt flow model advocated by Spiegelman and Reynolds (1999) and discussed in Sect. 4, in which melt is drawn to the narrow eruption zone by pressure gradients in the mantle flow. The porous-medium melt flow is also intrinsically a two-dimensional flow. The relationship between melt fraction and crustal thickness is a little more complicated in this case. All quantities here will be considered to be per unit length of the mid-ocean ridge (MOR). The mass of oceanic crust formed in a time $\delta t$ is

$M_{\mathrm{c}}=\rho_{\mathrm{c}} d_{\mathrm{c}} u \delta t$

where $\rho_{\mathrm{c}}$ is the density of oceanic crust and $\mathrm{U}$ is the half spreading rate of the MOR. The mass of mantle entering the melting zone over the same time interval is

$M_{\mathrm{m}}=\rho_{\mathrm{m}} w v \delta t$ (a)

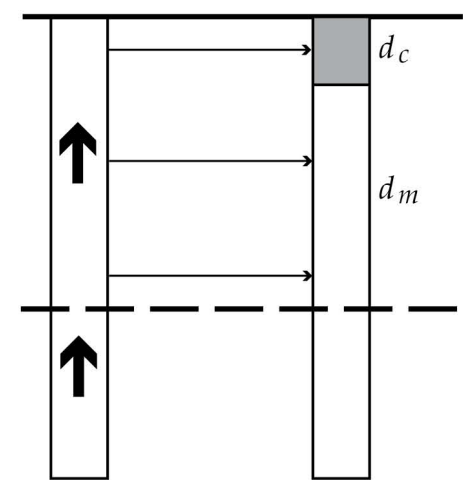

(b)

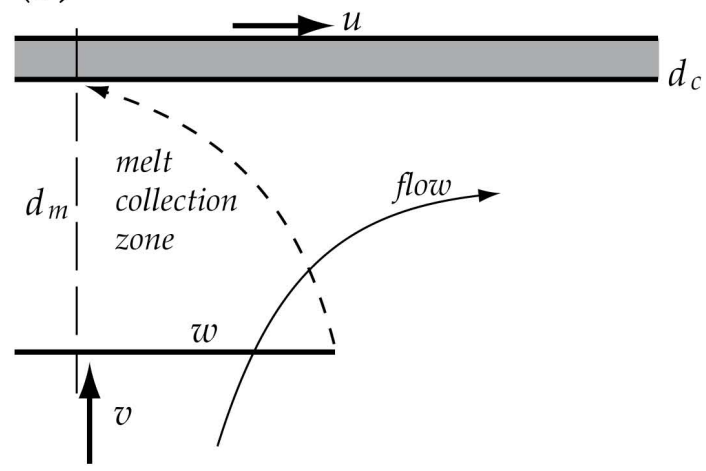

(c)

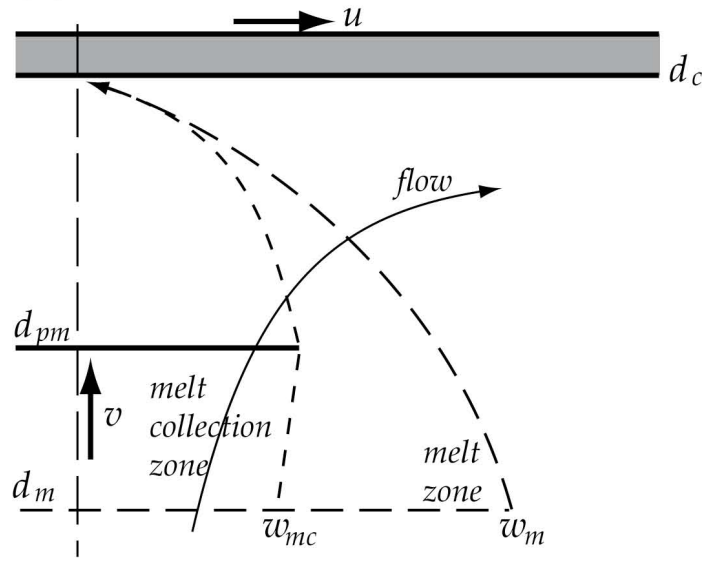

Fig. A1. Physical models of melting implicit in various formulae. (a) The column injection model implicit in the common formula relating melt fraction to thickness of oceanic crust. (b) A more realistic depiction of melting relationships in a homogeneous source, similar to Fig. 15a, involving two-dimensional flows of both the mantle and melt. (c) A depiction of melting relationships for a heterogeneous source, similar to Fig. 15b.

where $\rho_{\mathrm{m}}$ is the density of the mantle and $v$ is the ascent velocity of the mantle. The mass of melt formed will then be

$M_{\text {melt }}=f \rho_{\mathrm{m}} w v \delta t$ 
If the extraction of melt from the melt zone into the oceanic crust is $100 \%$ efficient, then $M_{\text {melt }}=M_{\mathrm{c}}$, so

$f \rho_{\mathrm{m}} w v \delta t=\rho_{\mathrm{c}} d_{\mathrm{c}} u \delta t$

from which we derive

$f=\rho_{\mathrm{c}} d_{\mathrm{c}} u / \rho_{\mathrm{m}} w v$

Now, if we ignore the density difference between the crust and the mantle, if $v=u$, and if the width of the melting zone, $w$, is proportional to the depth of melting, a reasonable assumption, so that $w=a d_{\mathrm{m}}$, where $a$ is a constant of proportionality, then

$f=d_{\mathrm{c}} / a d_{\mathrm{m}}$

Finally, if we know or assume that $a=1$ then we recover the simple relation (A1).

This analysis makes it clear that relation (A1) only applies if a number of conditions is true: the mantle ascent velocity equals the half spreading rate, the density difference between the crust and the mantle is ignored, the melt collection zone width is the same as the depth of first melting, and the melt extraction is $100 \%$ efficient. It is also possible for some of these factors to cancel others, by coincidence. Nevertheless these assumptions are not implausible if the source is homogeneous, as depicted in Fig. 15a. The uncertainties are probably similar to uncertainties in other aspects of the situation.

However the simple relationship (A1) is no longer accurate if the source is heterogeneous and melting is as depicted in Fig. 15b. Figure A1c is a sketch of the relevant quantities. Now the depth of first melting is $d_{\mathrm{m}}$, whereas the depth of peridotite melting, at which pervasive melt flow and melt "suction" begins, is $d_{\mathrm{pm}}$. The width of the melt collection zone is $w_{\mathrm{mc}}$, but the width of the zone over which eclogite and pyroxenite heterogeneities melt is $w_{\mathrm{m}}$.

Suppose the melt fraction is inferred from Eq. (A1), i.e. $f=d_{\mathrm{c}} / d_{\mathrm{m}}$. Now suppose the concentration of an incompatible trace element in the mantle, $c_{\mathrm{m}}$, is inferred from its concentration in the oceanic crust, $c_{\mathrm{c}}$, from the column melting model as

$c_{\mathrm{m}}=c_{\mathrm{c}} f=c_{\mathrm{c}} d_{\mathrm{c}} / d_{\mathrm{m}}$

If we grant the several assumptions required to reach Eq. (A6) with $a=1$, then the two-dimensional homogeneous model will yield the same answer.

Now let us calculate the mantle concentration from the heterogeneous model, Fig. A1c. The mass of mantle flowing into the melt collection zone is now $\rho_{\mathrm{m}} w_{\mathrm{mc}} v \delta t$ and the mass of melt formed will be $f_{\mathrm{h}} \rho_{\mathrm{m}} w_{\mathrm{mc}} v \delta t$, so the average melt fraction $f_{\mathrm{h}}$ in the heterogeneous case will be

$f_{\mathrm{h}}=\rho_{\mathrm{c}} d_{\mathrm{c}} / \rho_{\mathrm{m}} w_{\mathrm{mc}}$

If $w_{\mathrm{mc}}$ is considerably less than $w_{\mathrm{m}}$ (Fig. A1c) but $w_{\mathrm{mc}}$ is nevertheless equated to $d_{\mathrm{m}}$, as for the homogeneous case, then we can see from this Equation that $f_{\mathrm{h}}$ will be underestimated.

For example, suppose $d_{\mathrm{c}}=7 \mathrm{~km}$ and $w_{\mathrm{mc}}=49 \mathrm{~km}$. Then, ignoring density differences, $f_{\mathrm{h}}=1 / 7=0.143$. If an incompatible species has a concentration $c_{\mathrm{c}}$ in the crust, then its mantle concentration will be $c_{\mathrm{m}}=f_{\mathrm{h}} c_{\mathrm{c}}=c_{\mathrm{c}} / 7$. If, on the other hand, the usual formula is used, effectively equating $w_{\mathrm{mc}}$ to $d_{\mathrm{m}}$, and $d_{\mathrm{m}}=110 \mathrm{~km}$, then the melt fraction inferred from the standard formula will be $f_{\mathrm{s}}=7 / 110=0.064$ and the inferred mantle concentration of the incompatible species will be $c_{\mathrm{m}}=0.064 c_{\mathrm{c}}$. This will be too low by the factor $0.064 / 0.143=49 / 110=0.445$, in other words by more than a factor of 2 .

The qualitative effect of these relationships is that the crustal complement of the incompatible species is attributed to too large a mantle source volume (the melt zone instead of the melt collection zone in Fig. A1c) and so its mantle concentration is underestimated.

Acknowledgements. I would like to acknowledge the productive collaboration over three years of Jinshui Huang, the Research School of Earth Sciences of ANU for continuing my association through a visiting appointment, and detailed and constructive reviews by Matthew Jackson and Igor Tolstikhin.

Edited by: N. T. Arndt

\section{References}

Albarède, F.: Time-dependent models of U-Th-He and K-Ar evolution and the layering of mantle convection, Chem. Geol., 145, 413-429, 1998.

Albarède, F.: Rogue mantle helium and neon, Science, 319, 943945, 2008.

Allegre, C. J. and Turcotte, D. L.: Implications of a two-component marble-cake mantle, Nature, 323, 123-127, 1986.

Allegre, C. J., Staudacher, T., and Sarda, P.: Rare gas systematics: formation of the atmosphere, evolution and structure of the earth's mantle, Earth. Planet. Sci. Lett., 81, 127-150, 1987.

Allegre, C. J., Hofmann, A., and O'Nions, K.: The argon constraints on mantle structure, Geophys. Res. Lett., 23, 3555-3557, 1996.

Arevalo, R. J., McDonough, W. F., and Luong, M.: The K/U ratio of the silicate Earth: insights into mantle composition, structure and thermal evolution, Earth Planet. Sci. Lett., 278, 361-369, 2009.

Bennett, V. C., Brandon, A. D., and Nutman, A. P.: Hadean mantle dynamics from coupled 142-143 neodymium isotopes in Eoarchean rocks, Science, 318, 1907-1910, 2007.

Blichert-Toft, J. and Albarède, F.: Hafnium isotopes in Jack Hills zircons and the formation of the Hadean crust, Earth Planet. Sci. Lett., 265, 686-702, 2008.

Boyet, M. and Carlson, R. W.: ${ }^{142} \mathrm{Nd}$ evidence for early (>4.53 Ga) global differentiation of the silicate Earth, Science, 309, 576581, 2005.

Boyet, M. and Carlson, R. W.: A new geochemical model for the Earth's mantle inferred from ${ }^{146} \mathrm{Sm}-{ }^{142} \mathrm{Nd}$ systematics, Earth Planet. Sci. Lett., 250, 254-268, 2006. 
Brandenburg, J. P., Hauri, E. H., van Keken, P. E., and Ballantine, C. J.: A multiple-system study of the geochemical evolution of the mantle with force-balanced plates and thermochemical effects, Earth Planet. Sci. Lett., 276, 1-13, 2008.

Bunge, H.-P.: Low plume excess temperature and high core heat flux inferred from non-adiabatic geotherms in internally heated mantle circulation models, Phys. Earth Planet. Interiors, 153, 3$10,2005$.

Campbell, I. H. and Griffiths, R. W.: Implications of mantle plume structure for the evolution of flood basalts, Earth Planet. Sci. Lett., 99, 79-83, 1990.

Capitanio, F. A., Morra, G., and Goes, S.: Dynamics of plate bending at the trench and slab-plate coupling, Geochem. Geophys. Geosystems, 10, Q04002, doi:10.1029/2008GC002348, 2009.

Carlson, R. W. and Boyet, M.: Composition of the Earth's interior: the importance of early events, Phil. Trans. R. Soc. Lond. A, 366, 4077-4103, 2008.

Caro, G. and Bourdon, B.: Non-chondritic $\mathrm{Sm} / \mathrm{Nd}$ ratio in the terrestrial planets: Consequences for the geochemical evolution of the mantle-crust system, Geochim. Cosmochim. Acta, 74, 33333349, 2010.

Chase, C. G.: Oceanic island Pb: two-stage histories and mantle evolution, Earth Planet. Sci. Lett, 52, 277-284, 1981.

Christensen, U. R. and Hofmann, A. W.: Segregation of subducted oceanic crust in the convecting mantle, J. Geophys. Res., 99, 19,867-819,884, 1994.

Clague, D. A. and Dalrymple, G. B.: Tectonics, geochronology and origin of the Hawaiian-Emperor volcanic chain, in: The Eastern Pacific Ocean and Hawaii, edited by: Winterer, E. L., Hussong, D. M., and Decker, R. W., The Geology of North America, Geological Society of America, Boulder, Colo., 188-217, 1989.

Class, C. and Goldstein, S. L.: Evolution of helium isotopes in the Earth's mantle, Nature, 436, 1107-1112, 2005.

Cogné, J.-P. and Humler, E.: Global scale patterns of continental fragmentation: Wilson's cycles as a constraint for long-term sealevel changes, Earth Planet. Sci. Lett., 273, 251-259, 2008.

Davies, G. F.: Geophysical and isotopic constraints on mantle convection: an interim synthesis, J. Geophys. Res., 89, 6017-6040, 1984.

Davies, G. F.: Role of the lithosphere in mantle convection, J. Geophys. Res., 93, 10451-10466, 1988a.

Davies, G. F.: Ocean bathymetry and mantle convection, 1. Largescale flow and hotspots, J. Geophys. Res., 93, 10467-10480, 1988b.

Davies, G. F.: Heat and mass transport in the early earth, in: Origin of the Earth, edited by: Newsome, H. E. and Jones, J. H., Oxford University Press, 175-194, 1990a.

Davies, G. F.: Mantle plumes, mantle stirring and hotspot chemistry, Earth Planet Sci. Lett., 99, 94-109, 1990b.

Davies, G. F.: Temporal variation of the Hawaiian plume flux, Earth Planet. Sci. Lett., 113, 277-286, 1992.

Davies, G. F.: Cooling the core and mantle by plume and plate flows, Geophys. J. Int., 115, 132-146, 1993.

Davies, G. F.: Geophysically constrained mantle mass flows and the 40Ar budget: a degassed lower mantle?, Earth Planet. Sci. Lett, 166, 149-162, 1999a.

Davies, G. F.: Dynamic Earth: Plates, Plumes and Mantle Convection, Cambridge University Press, Cambridge, 460 pp., 1999 b.

Davies, G. F.: Stirring geochemistry in mantle convection mod- els with stiff plates and slabs, Geochim. Cosmochim. Acta, 66 , 3125-3142, 2002.

Davies, G. F.: Mantle regulation of core cooling: a geodynamo without core radioactivity?, Phys. Earth Planet. Interiors, 160, 215-229, 2007.

Davies, G. F.: Episodic layering of the early mantle by the "basalt barrier" mechanism, Earth Planet. Sci. Lett., 275, 382-392, 2008.

Davies, G. F.: Effect of plate bending on the Urey ratio and the thermal evolution of the mantle, Earth Planet. Sci. Lett., 287, 513-518, 2009a.

Davies, G. F.: Reconciling the geophysical and geochemical mantles: plume flows, heterogeneities and disequilibrium, Geochem. Geophys. Geosystems, 10, 19 pp., Q10008, doi:10.1029/2009GC002634, 2009b.

Davies, G. F.: Noble gases in the dynamic mantle, Geochem. Geophys. Geosystems, 11, Q03005, doi:03010.01029/02009GC002801, 2010.

Davies, G. F.: Mantle Convection for Geologists, Cambridge University Press, Cambridge, 240 pp., 2011.

Davies, G. F. and Richards, M. A.: Mantle convection, J. Geol., 100, 151-206, 1992.

Donnelly, K. E., Goldstein, S. L., Langmuir, C., and Spiegelman, M.: Origin of enriched ocean ridge basalts and implications for mantle dynamics, Earth Planet. Sci. Lett., 226, 347-366, 2004.

Farley, K. A., Maier-Reimer, E., Schlosser, P., and Broecker, W. S.: Constraints on mantle ${ }^{3} \mathrm{He}$ fluxes and deep-sea circulation from an ocean general circulation model, J. Geophys. Res., 100, 3829-3839, 1995.

Farnetani, C. G. and Samuel, H.: Beyond the thermal plume paradigm, Geophys. Res. Lett., 32, L07311, doi:07310.01029/02005GL022360, 2005.

Grand, S., van der Hilst, R. D., and Widiyantoro, S.: Global seismic tomography: a snapshot of convection in the earth., Geol. Soc. Amer. Today, 7, 1-7, 1997.

Griffiths, R. W. and Campbell, I. H.: Stirring and structure in mantle plumes, Earth Planet. Sci. Lett., 99, 66-78, 1990.

Gurnis, M. and Davies, G. F.: Mixing in numerical models of mantle convection incorporating plate kinematics, J. Geophys. Res., 91, 6375-6395, 1986.

Harper, C. L. and Jacobsen, S. B.: Evidence from coupled 147Sm$143 \mathrm{Nd}$ and $146 \mathrm{Sm}-142 \mathrm{Nd}$ systematics for very early $(4.5 \mathrm{Gyr})$ differentiation of the Earth's mantle, Nature, 360, 728-732, 1992.

Harrison, T. M., Blichert-Toft, J., Müller, W., Albarède, F., Holden, P., and Mojzsis, S. J.: Heterogeneous Hadean hafnium: evidence of continental crust at 4.4 to $4.5 \mathrm{Ga}$, Science, 310, 1947-1950, 2005.

Hirose, K.: Postperovskite phase transition and its geophysical implications, Rev. Geophys., 44, RG3001, doi:10.1029/2005RG000186, 2006.

Hirose, K., Takafuji, N., Sata, N., and Ohishi, Y.: Phase transition and density of subducted MORB crust in the lower mantle, Earth Planet. Sci. Lett., 237, 239-251, 2005.

Hofmann, A. W.: Chemical differentiation of the Earth: the relationship between mantle, continental crust, and oceanic crust, Earth Planet. Sci. Lett., 90, 297-314, 1988.

Hofmann, A. W.: Mantle chemistry: the message from oceanic volcanism, Nature, 385, 219-229, 1997. 
Hofmann, A. W.: Sampling mantle heterogeneity through oceanic basalts: isotopes and trace elements, in: Treatise on Geochemistry Vol 2: The Mantle and Core, edited by: Carlson, R. W., Treatise on Geochemistry, 2, Elsevier-Pergamon, Oxford, 1-44, 2003.

Hofmann, A. W. and Hart, S. R.: An assessment of local and regional isotopic equilibrium in the mantle, Earth Planet. Sci. Lett., 38, 4-62, 1978 .

Hofmann, A. W. and White, W. M.: Mantle plumes from ancient oceanic crust, Earth Planet. Sci. Lett., 57, 421-436, 1982.

Huang, J. and Davies, G. F.: Stirring in three-dimensional mantle convection models and its implications for geochemistry: Passive tracers, Geochem. Geophys. Geosystems, 8, Q03017, doi:03010.01029/02006GC001312, 2007a.

Huang, J. and Davies, G. F.: Stirring in three-dimensional mantle convection models and implications for geochemistry: 2 . Heavy tracers, Geochem. Geophys. Geosystems, 8, Q07004, doi:07010.01029/02007GC001621, 2007b.

Huang, J. and Davies, G. F.: Geochemical processing in a three-dimensional regional spherical shell model of mantle convection, Geochem. Geophys. Geosystems, 8, Q11010, doi:10.1029/2007GC001625, 2007c.

Ito, G. and Mahoney, J. J.: Melting a high $3 \mathrm{He} / 4 \mathrm{He}$ source in a heterogeneous mantle, Geochem. Geophys. Geosystems, 7(5), Q05010, doi:10.1029/2005GC001158, 2006.

Jackson, M. G., Carlson, R. W., Kurz, M. D., Kempton, P. D., Francis, D., and Blusztajn, J.: Evidence for the survival of the oldest terrestrial mantle reservoir, Nature, 466, 853-856, 2010.

Jochum, K. P., Hofmann, A. W., Ito, E., Seufert, H. M., and White, W. M.: K, U and Th in mid-ocean ridge basalt glasses and heat production, $\mathrm{K} / \mathrm{U}$ and $\mathrm{K} / \mathrm{Rb}$ in the mantle, Nature, 306, 431-436, 1983.

Kellogg, L. H. and Turcotte, D. L.: Mixing and the distribution of heterogeneities in a chaotically convecting mantle, J. Geophys. Res., 95, 421-432, 1990.

Kellogg, L. H., Hager, B. H., and van der Hilst, R. D.: Compositional stratification in the deep mantle, Science, 283, 1881-1884, 1999.

Kemp, A. I. S., Wilde, S. A., Hawkesworth, C. J., Coath, C. D., Nemchin, A., Pidgeon, R. T., Vervoort, J. D., and DuFrane, S. A.: Hadean crustal evolution revisited: New constraints from $\mathrm{Pb}-\mathrm{Hf}$ isotope systematics of the Jack Hills zircons, Earth Planet. Sci. Lett., 296, 45-56, 2010.

Kerr, R. C. and Mériaux, C.: Structure and dynamics of sheared mantle plumes, Geochem. Geophys. Geosyst., 5, Q12009, doi:12010.11029/12004GC000749, 2004.

Kogiso, T., Hirschmann, M. M., and Reiners, P. W.: Length scales of mantle heterogeneities and their relationship to ocean island basalt geochemistry, Geochim. Cosmochim. Acta, 68, 345-360, 2004.

Korenaga, J.: Archean geodynamics and the thermal evolution of the Earth, in: Archean Geodynamics and Environments, edited by: Benn, K., Mareschal, J.-C., and Condie, K. C., Geophysical Monograph Series, Amer. Geophys. Union, Washington D.C., 732, 2006.

Korenaga, J.: Eustasy, supercontinental insulation, and the temporal variability of terrestrial heat flux, Earth Planet. Sci. Lett., 257, 350-358, 2007.
Korenaga, J.: Urey ratio and the structure and evolution of Earth's mantle, Rev. Geophys., 46, RG2007, doi:10.1029/2007RG000241, 2008.

Kumagai, I., Davaille, A., Kurita, K., and Stutzmann, E.: Mantle plumes: Thin, fat, successful, or failing? Constraints to explain hot spot volcanism through time and space, Geophys. Res. Lett., 35, L16301, doi:16310.11029/12008GL035079, 2008.

Labrosse, S.: Hotspots, mantle plumes and core heat loss, Earth Planet. Sci. Lett., 199, 147-156, 2002.

Labrosse, S. and Jaupart, C.: Thermal evolution of the Earth: Secular changes and fluctuations of plate characteristics, Earth Planet. Sci. Lett., 260, 465-481, 2007.

Lassiter, J. C.: Role of recycled oceanic crust in the potassium and argon budget of the Earth: Toward a resolution of the "missing argon” problem, Geochem. Geophys. Geosystems, 5, Q11012, doi:10.1029/2004GC000711, 2004.

Lay, T., Williams, Q., and Garnero, E. J.: The core-mantle boundary layer and deep Earth dynamics, Nature, 392, 461-468, 1998.

Lay, T., Hernlund, J. W., and Buffett, B. A.: Core-mantle boundary heat flow, Nat. Geosci., 1, 25-32, 2008.

Leitch, A. M. and Davies, G. F.: Mantle plumes and flood basalts: Enhanced melting from plume ascent and an eclogite component, J. Geophys. Res., 106, 2047-2059, 2001.

Leng, W. and Zhong, S.: Controls on plume heat flux and plume excess temperature, J. Geophys. Res., 113, B04408, doi:10.1029/2007JB005155, 2008.

Lin, S. and van Keken, P. E.: Dynamics of thermochemical plumes: 2. Complexity of plume structures and its implications for mapping mantle plumes, Geochem. Geophys. Geosystems, 7, Q03003, doi:03010.01029/02005GC001072, 2006.

Lyubetskaya, T. and Korenaga, J.: Chemical composition of Earth's primitive mantle and its variance: 1 . Method and results, J. Geophys. Res., 112, B03211, doi:10.1029/2005JB004223, 2007.

McDonough, W. F.: Compositional model for the Earth's core, in: Treatise on Geochemistry, Vol. 2: The Mantle and Core, edited by: Carlson, R. W., Holland, H. D., and Turekian, K. K., Elsevier, Oxford, 547-569, 2003.

McDonough, W. F. and Sun, S.-S.: The composition of the Earth, Chem. Geol., 120, 223-253, 1995.

McDougall, I. and Honda, M.: Primordial solar noble-gas component in the earth: Consequences for the origin and evolution of the earth and its atmosphere, in: The Earth's Mantle: Composition, Structure and Evolution, edited by: Jackson, I. N. S., Cambridge University Press, Cambridge, 159-187, 1998.

Melosh, H. J.: Giant impacts and the thermal state of the early Earth, in: Origin of the Earth, edited by: Newsom, H. E., and Jones, J. H., Oxford University Press, 69-83, 1990.

Melosh, H. J. and Vickery, A. M.: Impact erosion of the primordial atmosphere of Mars, Nature, 338, 487-489, 1989.

O’Neil, J., Carlson, R. W., Francis, D., and Stevenson, R. K.: Neodymium-142 Evidence for Hadean Mafic Crust, Science, 321, 1828-1831, 2008.

O'Neill, H. S. C. and Palme, H.: Composition of the silicate Earth: implications for accretion and core formation, in: The Earth's Mantle: Composition, Structure and Evolution, edited by: Jackson, I. N. S., Cambridge University Press, Cambridge, 3-126, 1998.

Parman, S. W.: Helium isotopic evidence for episodic mantle melting and crustal growth, Nature, 446, 900-903, 2007. 
Parsons, B.: Causes and cosequences of the relation between area and age of the ocean floor, J. Geophys. Res., 87, 289-302, 1982.

Porcelli, D. and Wasserburg, G. J.: Mass transfer of helium, neon, argon and xenon through a steady-state upper mantle, Geochim. Cosmochim. Acta, 59, 4921-4937, 1995a.

Porcelli, D. and Wasserburg, G. J.: A unified model for terrestrial rare gases, in: Volatiles in the Earth and Solar System, edited by: Farley, K. A., AIP Press, New York, 56-69, 1995 b.

Ringwood, A. E.: Composition and Petrology of the Earth's Mantle, McGraw-Hill, 618 pp., 1975.

Rudnick, R. L. and Fountain, D. M.: Nature and composition of the continental crust: a lower crustal perspective, Rev. Geophys., 33, 267-309, 1995.

Salters, V. J. M. and Dick, H. J. B.: Mineralogy of the mid-oceanridge basalt source from neodymium isotopic composition of abyssal peridotites, Nature, 418, 68-72, 2002.

Salters, V. J. M. and Stracke, A.: Composition of the depleted mantle, Geochem. Geophys. Geosystems, 5, Q05B07, doi:10.1029/2003GC000597, 2004.

Silver, P. G. and Behn, M. D.: Intermittent plate tectonics?, Science, 319, 85-88, 2008.

Sleep, N. H.: Hotspots and mantle plumes: Some phenomenology, J. Geophys. Res., 95, 6715-6736, 1990.

Sobolev, A. V., Hofmann, A. W., Sobolev, S. V., and Nikogosian, I. K.: An olivine-free mantle source of Hawaiian shield basalts, Nature, 434, 590-597, 2005.

Sobolev, A. V., Hofmann, A. W., Kuzmin, D. V., Yaxley, G. M., Arndt, N. T., Chung, S.-L., Danyushevsky, L. V., Elliott, T., Frey, F. A., Garcia, M. O., Gurenko, A. A., Kamenetsky, V. S., Kerr, A. C., Krivolutskaya, N. A., Matvienkov, V. V., Nikogosian, I. K., Rocholl, A., Sigurdsson, I. A., Sushchevskaya, N. M., and Teklay, M.: The amount of recycled crust in sources of mantlederived melts, Science, 316, 412-417, 2007.

Spandler, C., Yaxley, G., Green, D. H., and Rosenthal, A.: Phase relations and melting of anhydrous K-bearing eclogites from 1200 to $1600^{\circ} \mathrm{C}$ and 3 to $5 \mathrm{GPa}$, J. Petrology, 49, 771-795, 2008.

Spiegelman, M. and Reynolds, J. R.: Combined dynamic and geochemical evidence for convergent melt flow beneath the East Pacific Rise, Nature, 402, 282-285, 1999.

Stacey, F. D.: Physics of the Earth, 3 Edn., Brookfield Press, Brisbane, 513 pp., 1992.

Starkey, N. A., Stuart, F. M., Ellam, R. M., Fitton, J. G., Basu, S., and Larsen, L. M.: Helium isotopes in early Iceland plume picrites: Constraints on the composition of high $3 \mathrm{He} / 4 \mathrm{He}$ mantle, Earth Planet. Sci. Lett., 277, 91-100, 2009.

Stevenson, D. J.: Fluid dynamics of core formation, in: Origin of the Earth, edited by: Newsom, H. E., and Jones, J. H., Oxford University Press, New York, 231-249, 1990.

Stuart, F. M., Lass-Evans, S., Fitton, J. G., and Ellam, R. M.: High $3 \mathrm{He} / 4 \mathrm{He}$ ratios in picritic basalts from Baffin Island and the role of a mixed reservoir in mantle plumes, Nature, 424, 57-59, 2003.

Sun, S.-S. and McDonough, W. F.: Chemical and isotopic characteristics of oceanic basalts: implications for mantle composition and processes, in: Magmatism in Ocean Basins, edited by: Saunders, A. D. and Norry, M. J., Geol. Soc. Am. Spec. Publ., 42, 313-345, 1988
Takahashi, E., Nakajima, K., and Wright, T. L.: Origin of the Columbia River basalts: Melting model of a heterogeneous plume head, Earth Planet. Sci. Lett., 162, 63-80, 1998.

Taylor, S. R. and McLennan, S. M.: The Continental Crust: Its Composition and Evolution, Blackwell, Oxford, 312 pp., 1985.

Tolstikhin, I. and Hofmann, A. W.: Early crust on top of the Earth's core, Phys. Earth Planet. Interiors, 148, 109-130, 2005.

Tolstikhin, I. N., Kramers, J. D., and Hofmann, A. W.: A chemical Earth model with whole mantle convection: The importance of a core-mantle boundary layer $\left(\mathrm{D}^{\prime \prime}\right)$ and its early formation, Chem. Geol., 226, 79-99, 2006.

Turcotte, D. L. and Oxburgh, E. R.: Finite amplitude convection cells and continental drift, J. Fluid Mech., 28, 29-42, 1967.

Turner, G.: The outgassing history of the earth's atmosphere, J. Geol. Soc. London, 146, 147-154, 1989.

Valley, J. W.: Early Earth, Elements, 2, 201-204, 2006.

van der Hilst, R. D. and Kárason, K.: Compositional heterogeneity in the bottom $1000 \mathrm{~km}$ of Earth's mantle: towards a hybrid convection model, Science, 283, 1885-1888, 1999.

van Keken, P. E. and Zhong, S.: Mixing in a 3D spherical model of present day mantle convection, Earth Planet. Sci. Lett., 171, 533-547, 1999.

Wasserburg, G. J. and DePaolo, D. J.: Models of earth structure inferred from neodymium and strontium isotopic abundances, Proc. Natl. Acad. Sci. USA, 76, 3594-3598, 1979.

White, W. M.: Sources of oceanic basalts: radiogenic isotopes evidence, Geology, 13, 115-118, 1985.

Wilson, J. T.: A new class of faults and their bearing on continental drift, Nature, 207, 343-347, 1965.

Workman, R. K. and Hart, S. R.: Major and trace element composition of the depleted MORB mantle (DMM), Earth Planet. Sci. Lett., 231, 53-72, 2005.

Wu, B., Conrad, C. P., Heuret, A., Lithgow-Bertelloni, C., and Lallemand, S.: Reconciling strong slab pull and weak plate bending: The plate motion constraint on the strength of mantle slabs, Earth Planet. Sci. Lett., 272, 412-421, 2008.

Xie, S. and Tackley, P. J.: Evolution of U-Pb and Sm-Nd systems in numerical models of mantle convection and plate tectonics, $\mathrm{J}$ Geophys. Res., 109, B11204, doi:10.1029/2004JB003176, 2004.

Yasuda, A., Fujii, T., and Kurita, K.: Melting phase relations of an anhydrous mid-ocean ridge basalt from 3 to $20 \mathrm{GPa}$ : Implications for the behavior of subducted oceanic crust in the mantle, J. Geophys. Res., 99, 9401-9414, 1994.

Yaxley, G.: Experimental study of the phase and melting relations of homogeneous basalt + peridotite mixtures and implications for the petrogenesis of flood basalts, Contrib. Mineral. Petr., 139, 326-338, 2000.

Zindler, A. and Hart, S.: Chemical geodynamics, Ann. Rev. Earth Planet. Sci., 14, 493-570, 1986. 